\title{
Inelastic neutron scattering study of reline: shedding light on the hydrogen bonding network of deep eutectic solvents
}

\author{
C. F. Araujo, J. A. P. Coutinho, M. M. Nolasco, \\ S. F. Parker, P. J. A. Ribeiro-Claro, S. Rudic, \\ B. I. G. Soares and P. D. Vaz
}

\section{Published version information}

Citation: CF Araujo et al. "Inelastic neutron scattering study of reline: shedding light on the hydrogen bonding network of deep eutectic solvents." Physical Chemistry Chemical Physics, vol. 19 (2017): 17998-18009.

DOI: $\underline{10.1039 / C 7 C P 01286 A}$

This version is made available in accordance with publisher policies. Please cite only the published version using the reference above. This is the citation assigned by the publisher at the time of issuing the AAM. Please check the publisher's website for any updates. 


\title{
Journal Name
}

\section{ARTICLE}

\section{Inelastic Neutron Scattering study of Reline: shedding light on the hydrogen bonding network of deep eutectic solvents}

Z<sdReceived 00th January 20xx, Accepted 00th January 20xx

DOI: $10.1039 / x 0 x \times 00000 x$

www.rsc.org/

\author{
C. F. Araujo ${ }^{a}{ }^{a}$, J. A. P. Coutinho ${ }^{a}$, M. M. Nolasco ${ }^{a}$, S.F. Parker ${ }^{b}$, P. J. A. Ribeiro-Claro \\ $+^{a}$, S. Rudić ${ }^{b}$, B. I. G. Soares ${ }^{a}$, P. D. Vaz ${ }^{b, c}$
}

\begin{abstract}
The solids choline chloride and urea, mixed in a 1:2 molar proportion, form the iconic deep eutectic solvent "Reline". A combination of computational and vibrational spectroscopy tools, including inelastic neutron scattering (INS), have been used to probe intermolecular interactions in the eutectic mixture. Reline's experimental spectra were estimated using discrete and periodic ab-initio calculations of a molecular aggregate with two choline chloride and four urea units. This is the minimum size required to achieve satisfactory agreement with experiment, as smaller clusters cannot represent all of Reline's significant intermolecular interactions. The INS spectrum of Reline, compared with that of pure choline chloride, reveals a displacement of chloride anions away from their preferred positions on top of choline's methyl groups, whose torsional movement becomes less hindered in the mixture. Urea, which adopts a planar (sp2) shape in the crystal, becomes non-planar (sp3) in Reline, a feature herein discussed for the first time. In Reline, urea molecules form a wide range of hydrogen bonds, from soft contacts to stronger associations, the latter being responsible for the deviation from ideality. The chloride's interactions with choline are largely conserved at the hydroxyl end while becoming weaker at the cationic headgroup. The interplay of soft and strong interactions confers flexibility to the newly formed hydrogen-bond network and allows the ensemble to remain liquid at room temperature.
\end{abstract}

\section{Introduction}

Deep eutectic solvents (DES) are a trending research topic ${ }^{1-7}$, fueled by the need to find sustainable alternatives to conventional solvents. DES's are binary mixtures of hydrogen bond donors and acceptors that are easy to prepare, and in general cheap, biodegradable and not very toxic. Their range of applications keeps growing, arguably much faster than our current understanding of their behavior. Grasping the mechanics of deep eutectic behavior is important in itself, far beyond the scope of practical applications, as

\footnotetext{
a. CICECO - Aveiro Institute of Materials, Departamento de Química, Universidade de Aveiro, 3810-193 Aveiro, Portugal

b. ISIS Neutron \& Muon Source, STFC Rutherford Appleton Laboratory, Chilton, Didcot,

OXfordshire OX11 OQX, UK

c. CQB, Departamento de Química e Bioquímica, Faculdade de Ciências da Universidade de Lisboa, 1749-016 Lisboa, Portugal.

† correspondence to: prc@ua.pt, catarina.araujo@ua.pt

Electronic Supplementary Information (ESI) available: [details of any supplementary information available should be included here]. See DOI: $10.1039 / x 0 x x 00000 x$
}

it addresses fundamental questions concerning the physical principles governing supramolecular chemistry.

The term "deep eutectic" stems from a peculiar phenomenon: at the eutectic point, the melting point of a DES is significantly lower than that of an ideal mixture of its components. "Reline", the most widely studied DES, is a blend of choline chloride $([\mathrm{Ch}] \mathrm{Cl})$ and urea in a molar ratio of $1: 2^{8}$. The term "Reline" is used for mere convenience and should not lead the reader to confuse this physical mixture with a new chemical compound. When anhydrous, the Reline mixture melts at $30{ }^{\circ} C^{9}$, while the corresponding ideal mixture would have a melting point close to $100 \stackrel{\circ}{ }$. The most often cited rationalization for this phenomenon is that urea, a hydrogen bond donor, interacts with the chloride anion thus disrupting choline chloride's lattice, leading to charge delocalization and preventing crystallization ${ }^{2,10}$. This view has been recently disputed by Zahn and colleagues ${ }^{11}$, whose ab-initio molecular dynamics simulation shows negligible charge transfer from the chloride anion 
to the urea molecule. Instead, charge spreads from the anion to the choline cation. Indeed, the newly formed urea-chloride interactions do not always lead to such drastic melting point depression. Mixtures of symmetric tetraalkylammonium chlorides with urea tend to form ordered structures with higher melting points ${ }^{12-14}$ a hint that entropy may also play an important role in the melting point depression.

A growing body of theoretical and experimental research ${ }^{10,15-32}$ is attempting to understand the molecular keys that unlock the deep eutectic behavior. Wagle and co-workers briefly reviewed ${ }^{21}$ the most relevant computational studies on DES. Since then, an abinitio study by Ashworth and colleagues ${ }^{15}$ explored the many possible hydrogen bonding interactions among Reline's constituents and quantified them in the atoms-in-molecules framework. The $\mathrm{O}-\mathrm{H}^{\prime \prime} \mathrm{O}=\mathrm{C}$ contacts stood out as the strongest, followed by $\mathrm{N}-\mathrm{H} \cdots \mathrm{O}=\mathrm{C}$ and $\mathrm{N}-\mathrm{H} \cdots \mathrm{Cl}$ hydrogen bonds. Interestingly, choline's $\mathrm{C}-\mathrm{H} \cdot \mathrm{Cl}$ interactions, although individually weak, become competitive with $\mathrm{N}-\mathrm{H} \cdot \mathrm{Cl}$ due to their tripodal arrangement (in the [Ch]Cl crystal each $\mathrm{Cl}$ sits at the top of three methyl groups, as depicted in Fig.1).

A neutron diffraction study by Hammond and his team ${ }^{16}$ confirms the ordering of hydrogen bonding strength proposed by Ashworth. Contrary to expectation, the radial distribution function of $\mathrm{OH} \cdots \mathrm{Cl}$ distances in Reline is centered at $2.1 \AA$, roughly the same distance as in the $[\mathrm{Ch}] \mathrm{Cl}$ crystal. Concurrently, the $\mathrm{CH}_{3}{ }^{\cdots} \mathrm{Cl}$ distance increases slightly, suggesting that the anions sitting on choline's headgroup are preferentially displaced, relative to the ones bonded to $\mathrm{OH}$.

While neutron diffraction provides information on the intermolecular distances, inelastic neutron scattering (INS), a vibrational spectroscopy tool, sheds light on the strength of intermolecular interactions ${ }^{33}$. INS has the advantage of probing low frequency modes, inaccessible by Raman and infrared techniques, which provide information on the 3D spatial arrangement of a system. In this paper, we present the INS spectra of Reline, collected on the TOSCA ${ }^{34,35}$ and MAPS ${ }^{33,36}$ instruments at ISIS-RAL (UK). The Raman and infrared vibrational spectra are also discussed. Although these have been examined before ${ }^{17,21-23,26,27,37}$, their assignment remains somewhat controversial and not all of the helpful information has been fleshed out. Instead of reviewing previous work here, the assignments made by other authors are directly compared with our own, in the discussion section.
In line with similar methodologies employed by Wagle ${ }^{21}$ and $\mathrm{Zhu}^{23}$, we have used the discrete cluster approximation to estimate Reline's vibrational spectrum. The most stable aggregate, shown in Figs. 1 and 2, was then used as the "unit cell" in a CASTEP ${ }^{38}$ calculation. The interpretation of Reline's INS spectrum was based on the results of both discrete and periodic calculations, as well as the assignments of the pure components.

\section{Methods}

\subsection{Eutectic mixture preparation}

Reline was prepared in a glovebox by mixing, in a 1:2 molar ratio, choline chloride (Acros Organics) and urea (Panreac) followed by heating at $60^{\circ} \mathrm{C}$. The reagents were previously dried under vacuum for three days to avoid water contamination, as it drastically affects Reline's properties $^{19}$. Partially and fully deuterated mixtures were prepared in the same manner. Urea-D4 (98 atom \% D) was purchased from Sigma-Aldrich while [Ch]Cl-OD was prepared by repeatedly washing with $\mathrm{D}_{2} \mathrm{O}$ and drying under vaccum and heating. The success of isotopic exchange was confirmed by the appearance of the VOD band at $2400 \mathrm{~cm}^{-1}$ in the FTIR spectrum and the $\mathrm{VOH} / \mathrm{VOD}$ intensity ratio suggests an exchange rate of $90 \%$. Initially, three 1:2 mixtures were prepared: [Ch]ClOD+Urea-H4 (total of 10 atom \% D), [Ch]ClOH+Urea-D4 (total of 87 atom \% D) and [Ch]ClOD+Urea-D4 (total of 97 atom \% D). Weeks later, a fourth was made from blending equal amounts of the first two, resulting in a total of $48 \%$ atom $D$.

\subsection{Spectrum acquisition}

The INS spectra of Reline and choline chloride were collected using the TOSCA and MAPS instruments at the ISIS pulsed spallation neutron and muon source of the STFC Rutherford Appleton Laboratory (Chilton, UK). The TOSCA spectrum of urea had been previously recorded by Johnson and colleagues ${ }^{39}$ and is available at the TOSCA database ${ }^{40}$ while its MAPS spectra were collected by us. The samples, weighing 2-3 g, were placed inside flat thin-walled aluminum cans which were then mounted perpendicular to the incident beam. The eutectic mixture, in the liquid state, was shockfrozen by quenching in liquid nitrogen. This procedure was used to avoid phase separation, although previous Raman studies of Reline subject to freezing-melting annealing cycles do not show signs of phase separation upon solidification. Spectra were collected below $20 \mathrm{~K}$. Raman spectra were measured at room temperature on a Bruker RFS/100S FT-Raman instrument with an Nd:YAG laser and using a resolution of $2 \mathrm{~cm}^{-1}$. The samples were enclosed in a quartz Raman cell for liquids. FTIR-ATR spectra were collected at room temperature on a FT Bruker IFS 55 spectrometer with a Golden Gate ATR accessory using a resolution of $2 \mathrm{~cm}^{-1}$. The samples were placed upon the optic window and covered with a metallic lid to prevent water contamination. 


\subsection{Discrete ab-initio calculations with Gaussian09}

Geometry optimizations and vibrational frequency calculations of isolated clusters in the gas phase were computed using the Gaussian $09^{41}$ software, at the B3LYP level of theory with the 6$31+G(d, p)$ basis set. The latter was selected as the best compromise between accuracy and efficiency among different functional/basis set combinations. The eigenvalues and eigenvectors from Gaussian's frequency calculation were then used by the ACLIMAX software $^{42}$ to estimate the intensities of the INS spectrum. For calculated Raman and infrared spectra, vibrational frequencies were scaled by a factor of $0.964{ }^{43}$ while INS spectra estimated with ACLIMAX were not scaled. Molecular geometries shown throughout the text were rendered using the QuteMol software ${ }^{44}$.

\subsection{Periodic ab-initio calculations with CASTEP}

Periodic density functional theory (periodic-DFT) calculations were carried out using the plane wave pseudopotential method as implemented in the CASTEP code ${ }^{38,45}$. Exchange and correlation were approximated using the PBE functional ${ }^{46}$. The plane-wave cutoff energy was $830 \mathrm{eV}$. Brillouin zone sampling of electronic states was performed on $8 \times 4 \times 4$ Monkhorst-Pack grid. The equilibrium structure, an essential prerequisite for lattice dynamics calculations was obtained by BFGS geometry optimization after which the residual forces were converged to zero within $\pm 0.005 \mathrm{eV} \cdot \mathrm{A}^{-1}$. Phonon frequencies were obtained by diagonalisation of dynamical matrices computed using density-functional perturbation theory ${ }^{47}$. The atomic displacements in each mode that are part of the CASTEP output, enable visualization of the modes to aid assignments and are also all that is required to generate the INS spectrum using the program ACLIMAX ${ }^{42}$. It is emphasised that for all the calculated spectra shown the transition energies have not been scaled.

\section{Results and discussion}

\subsection{Estimating Reline's spectra with discrete and periodic calculations}

As mentioned in the introduction, Wagle ${ }^{21}$ and $\mathrm{Zhu}^{23}$ have attempted to simulate Reline's vibrational spectrum using ab-initio calculations, albeit with moderate success. In both cases, Reline was modeled using the minimum cluster size of one $[\mathrm{Ch}] \mathrm{Cl}$ and two urea molecules. Better agreement between calculation and experiment requires expanding the model to include a greater variety of molecular contacts, representative of those we expect to find in Reline. For example, a minimum of two choline cations is needed to illustrate both $\mathrm{OH}^{* \cdots} \mathrm{O}=\mathrm{C}$ and $\mathrm{OH}^{\prime} \mathrm{Cl}$ bonding scenarios, as well as "head-to-tail" and centrosymmetric urea" urea contacts. Based on the intermolecular distances measured in Hammond's work ${ }^{16}$ and on the geometry of the lowest energy $1[\mathrm{Ch}] \mathrm{Cl}$ : 2 Urea clusters, a larger unit $(2[\mathrm{Ch}] \mathrm{Cl}: 4$ Urea) was built and optimized. This extended cluster, depicted in Fig. 1 and schematically with the intermolecular interactions included, in Fig.2, is the most stable of a few starting structures although, admittedly, the PES search was rather limited. By widening the array of hydrogen bonds represented in the model, depicted in Figs. 1 and 2, much better agreement with experiment was achieved. Note, however, that modelling a liquid using a small discrete cluster is akin to representing a whole movie by a single, zoomed-in frame - thus one must not rely solely on the computational model as a basis for vibrational assignments but rather complement it through comparison with related compounds. The INS spectra calculated using ACLIMAX ${ }^{42}$ are displayed in Fig. 3 (FTIR and Raman spectra, as estimated by discrete calculations, are shown in the supplementary material).

INS spectra collected using TOSCA are shown in Fig. 3 and Fig.S2 (ESI). TOSCA is optimised for the fingerprint region $\left(0-1600 \mathrm{~cm}^{-1}\right)$, so that for higher regions the signal intensity is very weak ${ }^{33}$ leading to poor resolution, as depicted in Fig. S3 (ESI). The region above 200 $\mathrm{cm}^{-1}$ in Reline's INS spectrum is satisfactorily described by the discrete cluster approximation (Fig. 3). As expected, the simulation fails for the lowest frequency region, which may only be adequately represented by a three-dimensional lattice. Even though shockfrozen Reline is expected to be quite amorphous, an attempt was made to simulate its phonon modes by creating a 3D array of extended clusters and optimizing it using the CASTEP code. This crude approximation did not succeed in replicating Reline's low frequency modes. As for the remaining regions of the INS spectrum, the discrete cluster and periodic calculations perform similarly in reproducing the experimental spectrum. The advantage of the resource intensive periodic calculation over the much more expeditous discrete route is a better representation of the pure compounds, whose crystalline structures are impossible to reproduce using a small cluster. Therefore, a realistic comparison of calculated and observed frequency shifts when going from pure compounds to their eutectic mixture requires sound models of the pure crystal lattices.

Discrete and periodic calculations, complemented by the wellestablished vibrational analysis of choline chloride ${ }^{48}$ and urea $^{39,49}$, have guided the spectral assignment of Reline's INS spectrum, presented in Fig. 4 and Table S2 (ESI).

\subsection{Vibrational analysis of low frequency modes: $<500 \mathrm{~cm}^{-1}$}

The spectrum of the mixture is clearly interaction-dependent, as it cannot be generated by the weighted sum of the spectra of the pure components, as shown in Fig. 4. Moreover, the differences between the spectrum of the mixture and the pure compounds are quite large, evidence for a strong interaction between the two. The sharp modes found below $200 \mathrm{~cm}^{-1}$ in the INS spectra of choline chloride and urea are the external, or lattice, modes. Lattice modes result from collective movements where whole molecules undergo either translation or rotation relative to the crystalline cell axes. Given the same molecular entity, diverse packing arrangements produce distinct spectral profiles. In the INS spectrum of Reline a 
very broad profile contrasts with the well-defined lattice peaks of choline chloride and urea, reflecting the total disruption of crystalline order and formation of a diverse and flexible hydrogen bond network within the eutectic mixture. The featureless profile is

\begin{tabular}{|c|c|c|c|c|c|c|}
\hline \multirow{2}{*}{ Vibrational mode } & \multicolumn{3}{|c|}{$\begin{array}{l}\text { Experimental frequency/ } \\
\qquad \mathrm{cm}^{-1}\end{array}$} & \multicolumn{3}{|c|}{$\begin{array}{l}\text { Estimated frequency (CASTEP)/ } \\
\qquad \mathrm{cm}^{-1}\end{array}$} \\
\hline & ChCl & Reline & $\Delta$ & ChCl & Reline & $\Delta$ \\
\hline In-phase torsion, $\tau_{1}$ & & & & & & \\
\hline $\begin{array}{c}\text { t-of-phase torsion, } \\
\tau_{2}\end{array}$ & 341 & 296 & -45 & 340 & 288 & -52 \\
\hline $\begin{array}{l}\text { Out-of-phase } \\
\text { torsion, } \tau_{3}\end{array}$ & 349 & 333 & -16 & 351 & 327 & -24 \\
\hline
\end{tabular}

reminiscent of that found in glasses ${ }^{50}$.

Above $200 \mathrm{~cm}^{-1}$ are the internal modes resulting from torsions and deformations of the molecular skeleton. In this region, all the bands

found in the Reline spectrum have a direct counterpart in the spectra of either of the pure components, with the notable exception of the band at $252 \mathrm{~cm}^{-1}$. Modes in the $300-500 \mathrm{~cm}^{-1}$ interval result from choline's $\mathrm{CH}_{3}$ torsions and $\mathrm{N}\left(\mathrm{CH}_{3}\right)_{3}$ deformations $^{48}$. Both periodic and discrete calculations suggest these to be complex, with a small contribution of $\mathrm{NH}_{2}$ wagging vibrations which may accentuate the broadening of Reline's bands, relative to those of choline chloride. In INS spectra, intensity correlates with atomic motion, and is particularly sensitive to the motion of hydrogen atoms. In a $1[\mathrm{Ch}] \mathrm{Cl}: 2$ Urea mixture, there are 14 hydrogens from choline for every 8 hydrogens from urea. Consequently, the vibrational modes involving choline's C-H moieties are the more prominent in Reline's INS spectrum, often obscuring those from urea.

\subsubsection{Chloride anions move away from choline's headroup}

The most striking feature in Reline's INS spectrum is the new band found at $252 \mathrm{~cm}^{-1}$. Intense modes in the $200-300 \mathrm{~cm}^{-1}$ region of the INS spectra are usually associated with torsions of methyl groups attached to a carbon atom ${ }^{51}$. In pure choline chloride ${ }^{48}$, methyl torsions appear as sharp peaks at $286 \mathrm{~cm}^{-1}, 341 \mathrm{~cm}^{-1}$ and $349 \mathrm{~cm}^{-1}$, as highlighted in Fig 4 . These modes are satisfactorily represented by the CASTEP calculation of the choline chloride crystal, as shown in Table 1. The corresponding torsional modes in Reline - clearly identified by displacement vectors denoting the hindered rotation of methyl groups around the $\mathrm{C}-\mathrm{N}$ bond - represent the strongest contribution to the calculated INS intensity in the $200-400 \mathrm{~cm}^{-1}$ region. The calculated methyl torsion frequencies can be unequivocally matched with the three maxima at $252 \mathrm{~cm}^{-1}, 296 \mathrm{~cm}^{-1}$ and $333 \mathrm{~cm}^{-1}$ in Reline's experimental spectrum, depicted in Fig 4. The experimental frequency shifts, relative to the choline chloride crystal, are in good agreement with those estimated in silico, as attested in Table 1.

Table 1 - Wavenumbers at maximum intensity of $\mathrm{ChCl}$ and Reline's methyl torsional modes, as observed experimentally (TOSCA) and estimated in a periodic $a b$ initio calculation (CASTEP)

Methyl torsions are very sensitive to their environment ${ }^{52,53}$. For the tetramethylammonium cation, methyl torsions are found to signal 'emptier' space in their surroundings: on moving from the crystal to inside zeolites, methyl torsion frequency drops according to the size of the cage, the lowest approaching $200 \mathrm{~cm}^{-1}$ for larger cavities $^{54}$. The red-shift in Reline's torsional modes results from changes in the chemical surroundings of choline's headgroup. In choline chloride, each methyl group is surrounded by chloride anions. A downshift of their torsion frequencies in Reline seems to reveal more free space around choline's cationic core. This observation is consistent with the notion that the newly added urea molecules competitively interact with chloride, effectively snatching it away from its equilibrium position in the crystal through the formation of $\mathrm{N}-\mathrm{H}$... Cl bonds. Hammond's neutron diffraction study ${ }^{16}$ of Reline reveals the distance between choline's methyl hydrogens and chloride to be a distribution centered at $3 \AA$. In crystalline choline chloride, the histogram of the shorter $\mathrm{CH}_{3}{ }^{\cdots} \mathrm{Cl}^{-}$ distances (as measured from the cif file available at the CCDC database with RefCode:CHOCHLO1) may be described by a binomial distribution centered at $2.9 \AA \AA$. On the other hand, choline cations seem to come closer together in Reline, where the average $N \cdots N$ distance between choline cations is $6.0 \AA$, while in the pure crystal it is $6.2 \AA$. These results support the hypothesis that in Reline the cations are pushed together while chloride anions move farther away from choline's methyl groups, resulting in more free space in their surroundings which lowers the torsional barrier causing a drop in the torsional mode frequency.

It should be mentioned that two alternative explanations for the appearance of the band at $252 \mathrm{~cm}^{-1}$ were also considered, involving the blue shift of either urea's $188 \mathrm{~cm}^{-1}$ band or choline's $211 \mathrm{~cm}^{-1}$ band (see Fig. 4). The band at $188 \mathrm{~cm}^{-1}$ is the E3 librational lattice mode of urea, a mode expected to be significantly perturbed upon disruption of the crystal network. Accordingly, calculations estimate urea's librational mode to originate several close bands in the 130$190 \mathrm{~cm}^{-1}$ region in Reline, contributing to the higher frequency side of the very broad profile found in the first $200 \mathrm{~cm}^{-1}$ of Reline's spectra. In what concerns the choline chloride's band at $211 \mathrm{~cm}^{-1}$, previously identified as a C-C torsion ${ }^{48}$, both discrete and periodic calculations suggest it also involves an intermolecular stretching of the $\mathrm{OH}^{\cdots} \mathrm{Cl}$ bond. The strengthening of hydrogen bonds established by $\mathrm{OH}$ to cause a blue shift would result in the concomitant decrease in $\mathrm{O}-\mathrm{H}$ stretching frequency, which is not observed experimentally, as discussed in another section. Moreover, both periodic and discrete calculations predict the C-C torsion/intermolecular stretch mode to spread among closely lying modes under $180 \mathrm{~cm}^{-1}$. This may be an additional contribution to 
the weak broad band seen in the $160-180 \mathrm{~cm}^{-1}$ region of Reline's spectrum.

\subsection{Vibrational analysis of skeletal modes: $500-1700 \mathrm{~cm}^{-1}$}

The INS spectrum recorded at TOSCA primarily targets the low wavenumber region, degrading in resolution with increasing energy transfer. The MAPS instrument, more flexible than TOSCA, allows a better description of the high wavenumber region, so the spectra recorded with MAPS will be shown, along with FTIR and Raman for ease of interpretation. Although the latter have been previously discussed, a few interesting details concerning the skeletal mode region have yet to be brought to light.

One such curious feature in the Raman spectrum of Reline, shown in Fig. 5, is the appearance of a new band signaling the presence of a choline conformer which is not present in the $[\mathrm{Ch}] \mathrm{Cl}$ crystal.

\subsubsection{Small population of trans choline conformer in the liquid mixture}

Choline's v CN modes are sensitive to the conformation of the $\mathrm{N}^{+}-\mathrm{C}-$ $\mathrm{C}-\mathrm{O}$ backbone, which may assume the gauche or trans configuration $^{55}$. In the choline chloride crystal only the gauche form is present, as signaled by the presence of a strong and sharp band at $719 \mathrm{~cm}^{-1}$, assigned to the symmetric $\vee \mathrm{C}-\mathrm{N}$. In the eutectic mixture, the corresponding $\vee \mathrm{C}-\mathrm{N}$ mode is found at $714 \mathrm{~cm}^{-1}$. A weak band at $767 \mathrm{~cm}^{-1}$ is a novel feature of Reline, having no counterpart in the pure components spectra. An analogous mixture with deuterated urea reveals that the $767 \mathrm{~cm}^{-1}$ band remains in place, therefore the latter originates from the choline cation, pointing to the existence of choline in the trans conformation. The weak intensity of this band, compared to the one at $714 \mathrm{~cm}^{-1}$, suggests that the gauche form still predominates in the liquid. Similarly, in aqueous solutions of choline iodide ${ }^{55}$, the trans conformer is a minority species. The $767 \mathrm{~cm}^{-1}$ band in Reline's Raman spectrum disappears when the mixture undergoes pressure induced crystallization ${ }^{26}$, confirming the notion that the trans conformation is not energetically accessible in solid form, a disadvantage likely stemming from its bent orbital alignment ${ }^{15}$. While the majority of choline cations conserve their structure upon forming the eutectic, urea undergoes a more drastic change in shape.

\subsubsection{Urea's shape in reline is pyramidal}

Urea's structure is classically understood as an equilibrium among resonance forms ${ }^{49,56,57}$. The mesomer population ratio varies in adaptation to the environment resulting in a planar structure, as found in the crystal, or deviating from planarity, as in the gas phase ${ }^{58-60}$. In Reline, urea adopts a non-planar shape, as depicted in Fig. 6. In the gas phase, urea's dominant mesomer has sp3 hybridization at the $\mathrm{N}$ atom, resulting in pyramidal $\mathrm{NH}_{2}$ groups, and the $\mathrm{C}=\mathrm{O}$ has double bond character. However, the lone pair located at $\mathrm{N}$ is in resonance with the $\mathrm{C}=\mathrm{O}$ bond. As the latter accepts hydrogen bonds, its bond order reduces while the lone pair's density delocalizes across the peptide linkage, strengthening the $\mathrm{C}-$ $\mathrm{N}$ bond. The resulting hybridization of $\mathrm{sp} 2+\mathrm{p}$ forces the $\mathrm{NH}_{2}$ moieties into the planar geometry found in urea's crystal.

Variations in the C-N bond length will be reflected in the frequency of its stretching and deformation vibrations, with lower frequencies indicating weaker $\mathrm{C}-\mathrm{N}$ bonds, hence higher relative contribution of non-planar resonance structures. Urea's $\mathrm{v}_{\text {sym }} \mathrm{C}-\mathrm{N}$, very intense in the Raman spectrum, often serves as a probe of urea's shape in different media ${ }^{49}$. In the spectrum of the crystal $\mathrm{v}_{\text {sym }} \mathrm{C}-\mathrm{N}$ is at 1010 $\mathrm{cm}^{-1}$ yet in the gas phase, a band at $934 \mathrm{~cm}^{-1}$ announces the weak $\mathrm{C}-\mathrm{N}$ bond typical of the pyramidal (sp3) arrangement. In aqueous solution, a $v_{\text {sym }} \mathrm{C}-\mathrm{N}$ at $1003 \mathrm{~cm}^{-1}$ indicates an intermediate shape which lies closer to planarity than to full pyramidality. In Reline, urea is slightly more pyramidal than in water, as indicated by the broad band centered at $996 \mathrm{~cm}^{-1}$ in the Raman spectrum shown in Fig. 7. Accordingly, the $\mathrm{v}_{\text {asym }} \mathrm{C}-\mathrm{N}$ and $\delta \mathrm{NCN}$ vibrations also undergo red-shift and broadening when going from the crystal to the mixture. The broad nature of these bands in Reline is a reflection of urea's greater structural flexibility in the liquid.

Another consequence of urea's non planarity in Reline is the shift of the vCO and $\delta \mathrm{NH}_{2}$ modes, whose highly coupled nature complicates their assignment, as attested by the conflicting attributions found in the literature. Due to the resonant stabilization mentioned above, the $v C O$ and $\delta \mathrm{NH}_{2}$ vibrational modes are coupled and both contribute to the bands found in the $1500-1700 \mathrm{~cm}^{-1}$ region of urea's infrared spectrum. According to Keuleers and co-workers ${ }^{49}$, the band at lower frequency $\left(1598 \mathrm{~cm}^{-1}\right)$ has more vCO character while the one at higher frequency $\left(1683 \mathrm{~cm}^{-1}\right)$ has greater $\delta \mathrm{NH}_{2}$ contribution. The order reverses as one goes from the crystal to the non-planar urea molecule in the gas phase where vCO sits at 1734 $\mathrm{cm}^{-1}$ while $\delta \mathrm{NH}_{2}$ is found at $1592 \mathrm{~cm}^{-1}$. Hence, the positioning of these vibrational modes, just as the $\mathrm{C}-\mathrm{N}$ modes discussed above, serve as a probe of urea's shape in a given medium.

In Reline's infrared spectrum (Fig.8b), two broad bands with maxima at 1606 and $1660 \mathrm{~cm}^{-1}$ are visible in the $1500-1700 \mathrm{~cm}^{-1}$ region. It has been unclear, so far, which of these bands has a higher contribution of $v \mathrm{CO}$, with some authors ${ }^{17,22}$ arguing that it is the lower frequency band, as in crystalline urea, while others claim the reverse is true ${ }^{21,23,37}$.

Distinguishing the nature of each mode is easier in the INS spectrum of Reline, presented in Figure 8a) along with those of choline chloride and urea. Due to the motion of hydrogen atoms dominating INS spectra, the $\delta \mathrm{NH}_{2}$ mode is stronger than $v C \mathrm{CO}$, as clearly seen in urea's INS spectrum, where the band at $1650 \mathrm{~cm}^{-1}$ registers the higher intensity. In Reline's INS spectrum, the corresponding band is in the $1620 \mathrm{~cm}^{-1}$ region, indicating a reversing of the $v \mathrm{CO}$ and $\delta \mathrm{NH}_{2}$ positions relative to the urea crystal. 
The new position of $v C O$ is confirmed by the infrared spectrum of a eutectic mixture prepared with deuterated urea, depicted in Fig. $8 b)$, showing a broad band at $1612 \mathrm{~cm}^{-1}$. This band corresponds to the pure vCO vibration. As a result of deuteration, $\delta \mathrm{NH}_{2}$ has moved downfield to the $1200 \mathrm{~cm}^{-1}$ region, thus decoupling from vCO. Discrete ab-initio calculations of the deuterated eutectic mixture predict that upon isotopic exchange the vCO band shifts down by 40 $\mathrm{cm}^{-1}$ and registers an infrared intensity increase of $50 \%$. Accordingly, the $1660 \mathrm{~cm}^{-1}$ band in Reline red-shifts by $48 \mathrm{~cm}^{-1}$ and increases in intensity by $40 \%$.

The spectroscopic evidence herein presented suffices to confidently assign the $1660 \mathrm{~cm}^{-1}$ band as the one with stronger vCO component while the one at $1606 \mathrm{~cm}^{-1}$ has greater $\delta \mathrm{NH}_{2}$ contribution. This situation is equivalent to that of urea in aqueous solutions ${ }^{49}$, where $v C O$ is the higher frequency band, at $1664 \mathrm{~cm}^{-1}$ while $\delta \mathrm{NH}_{2}$ is downfield, at $1592 \mathrm{~cm}^{-1}$. Therefore, urea's shape in Reline is nonplanar, an intermediate state between the fully planar (sp2) structure found in the crystal and the pyramidal (sp3) shape it adopts in the gas phase.

\subsection{Vibrational analysis of stretching modes: $3000-3600 \mathrm{~cm}^{-1}$}

The infrared spectra of the eutectic mixture and its pure components are depicted in Fig. 9. The greatest changes occur in the region above $3000 \mathrm{~cm}^{-1}$, where urea's $\mathrm{N}-\mathrm{H}$ and choline's $\mathrm{O}-\mathrm{H}$ stretching modes lie, the latter having a modest contribution due the low $\mathrm{OH} / \mathrm{NH}$ ratio $(1 / 8)$. The complex profile of this spectral region may be divided into three main sections: a lower frequency band at $3188 \mathrm{~cm}^{-1}$, a central component with a maximum at 3315 $\mathrm{cm}^{-1}$ plus a higher frequency shoulder at $3417 \mathrm{~cm}^{-1}$. The estimated infrared spectrum of Reline, calculated using the discrete model, reveals several vibrational modes which contribute to this structured profile, depicted in Fig. 10. According to the model:

- The high frequency shoulder at $3417 \mathrm{~cm}^{-1}$ stems from urea's $\mathrm{NH}_{2}$ asymmetric stretching modes;

- the central region at $3315 \mathrm{~cm}^{-1}$ arises from the symmetric stretching of $\mathrm{NH}_{2}$ moieties involved in $\mathrm{NH}^{*} \mathrm{OH}, \mathrm{NH}^{\prime \prime} \mathrm{Cl}^{-}$ and $\mathrm{NH}^{\prime \prime} \mathrm{O}=\mathrm{C}$ "head-to-tail" contacts;

- the low frequency band at $3188 \mathrm{~cm}^{-1}$ is a composite of O$\mathrm{H}$ and $\mathrm{N}-\mathrm{H}$ stretching of moieties involved in $\mathrm{OH}^{\prime \prime} \mathrm{Cl}^{\prime}$, $\mathrm{OH}^{\prime \prime} \mathrm{O}=\mathrm{C}$ and $\mathrm{NH}^{\prime \prime} \mathrm{O}=\mathrm{C}$ centrosymmetric dimer contacts.

As mentioned before, one must be careful not to rely heavily on a discrete calculation when simulating a liquid, especially so in the stretching region, where a realistic representation would require a much larger and dynamic model. Nevertheless, the calculated frequencies provide a guide of the main contributions to each region of the experimental spectrum - which should be complemented, where appropriate, by comparisons with parent compounds and previous assignments made by other authors.

\subsubsection{Stretching $\mathrm{N}-\mathrm{H}$ region, revisited}

The assignment of the higher wavenumber components of this region is straightforward, although the significance of the observed vibrational shifts deserves further discussion. In the infrared spectrum of pure urea (Fig. 9), two strong bands at $3333 \mathrm{~cm}^{-1}$ and $3427 \mathrm{~cm}^{-1}$ are assigned to $\mathrm{v}_{\mathrm{s}} \mathrm{NH}_{2}$ and $\mathrm{v}_{\mathrm{as}} \mathrm{NH}_{2}$, respectively. The corresponding modes in Reline's spectrum give rise to the maximum at $3315 \mathrm{~cm}^{-1}$ and the shoulder at $3417 \mathrm{~cm}^{-1}$. Their significant broadening reflects the increase in spatial heterogeneity of the liquid mixture, compared with the strictly ordered urea crystal. The small red-shifts of -18 and $-10 \mathrm{~cm}^{-1}$ have been previously interpreted as an indicator of the $\mathrm{N}-\mathrm{H}^{*} \mathrm{X} X$ hydrogen bond strengthening in Reline ${ }^{17}$.

If hydrogen bonding was the only effect at play, this direct reasoning would hold true. However, changing from a planar (sp2) into a pyramidal (sp3) configuration weakens the $\mathrm{N}-\mathrm{H}$ bond, leading by itself to a significant red-shift of the $\mathrm{vNH}_{2}$ modes ${ }^{61}$. Discrete abinitio calculations predict $\mathrm{v}_{\mathrm{s}} \mathrm{NH}_{2}$ and $\mathrm{v}_{\mathrm{as}} \mathrm{NH}_{2}$ to red-shift by $-38 \mathrm{~cm}^{-1}$ and $-55 \mathrm{~cm}^{-1}$, respectively, when going from planar to pyramidal urea. The shift between crystalline urea and urea in Reline must be lower, since the shape of urea in the mixture is far from the fully pyramidal (sp3) configuration found in the gas phase (see Figs. 6, 7 and related discussion). In fact, considering the isolated urea shape to be $100 \%$ pyramidal and using the vsCN frequency as a gauge of pyramidality, one estimates that in Reline urea is $20 \%$ pyramidal. Therefore, loss of planarity alone accounts for shifts of approximately $-8 \mathrm{~cm}^{-1}$ and $-11 \mathrm{~cm}^{-1}$ in urea's $\mathrm{v}_{\mathrm{s}} \mathrm{NH}_{2}$ and $\mathrm{v}_{\mathrm{as}} \mathrm{NH}_{2}$ modes. The observed red-shifts, which are close to those estimated for the loss of planarity's contribution, are then unlikely to stem from a strengthening of urea' urea interactions in Reline. This result is to be expected, since the extensively cooperative hydrogen bond network found in crystalline urea $^{62}$ is disrupted in the eutectic mixture giving rise to softer $\mathrm{NH} \mathrm{H}^{\cdots} \mathrm{OH}$ contacts as well as $\mathrm{N}-\mathrm{H} \mathrm{H}^{\cdots} \mathrm{O}=\mathrm{C}$ bonds in a "head-to-tail" motif whose $\mathrm{v}_{\mathrm{s}} \mathrm{NH}_{2}$ modes contribute to the absorption intensity in the $3315 \mathrm{~cm}^{-1}$ region. If this was not the case, molecular mobility would be restricted and Reline would likely melt at higher temperatures.

The assignment of the lower frequency component, centred at ca. $3188 \mathrm{~cm}^{-1}$, is a matter of some controversy. There is reason to believe this band is a composite of several contributions, including newly formed interactions partly responsible for the deviation from ideality that justify the pronounced melting point depression of reline.

This band has been ascribed ${ }^{17}$ to a combination mode in Fermi resonance with $\mathrm{vNH}_{2}$, by analogy to the shoulder observed in crystalline urea at $3256 \mathrm{~cm}^{-1}$. Although this contribution may be present, it is unlikely to account for the total intensity of the band. Another modest contribution is from choline's $\mathrm{vOH}$, expected to generate a broad band in this region (see discussion below). The 
remainder of the lower frequency band's intensity must then be accounted for by urea's vN-H modes. This claim is supported by the increase in intensity at $3188 \mathrm{~cm}^{-1}$ when doubling the molar fraction of urea, going from the equimolar choline chloride/urea mixture, shown in Fig. 9 as [Ch]Cl:Urea 1:1, to the eutectic mixture (Reline). Since no more $\mathrm{OH}$ groups were introduced, the greater intensity must be attributed to the formation of stronger $\mathrm{N}-\mathrm{H}^{*} \mathrm{X}$ X hydrogen bonds.

The often cited driving force for the melting point depression involves the formation of stronger hydrogen bonds between a subpopulation of urea molecules and chloride anions. One would expect to find their $\mathrm{VNH}$ modes at lower frequencies and thus assume that $\mathrm{N}-\mathrm{H}^{\prime} \mathrm{Cl}^{-}$moieties would contribute to the intense band at $3188 \mathrm{~cm}^{-1}$ in Reline's infrared spectrum, as suggested earlier by Wagle $^{21}$ and colleagues. This is a feasible hypothesis, since the infrared spectrum of urea hydrochloride ${ }^{63}$ has an intense band centered roughly at $3200 \mathrm{~cm}^{-1}$. However, the discrete model places these modes in the central region of the spectrum. In the absence of sufficiently strong evidence to locate the $\mathrm{vNH} . . . \mathrm{Cl}^{-}$mode we are thus unable to ascertain whether the formation of strong urea"'chloride bonds is, as has been believed, or isn't, an important factor leading to the melting point depression.

Instead, it is safe to assume that another factor, not discussed before, plays an important role in Reline's deviation from ideality. There is theoretical and experimental evidence for the formation of centrosymmetric urea dimers, held by strong hydrogen bonds ${ }^{64}$ which contribute to the $3188 \mathrm{~cm}^{-1}$ band of Reline's infrared spectrum. As shown in Fig. 10, discrete ab-initio calculations indicate the $\mathrm{vN}-\mathrm{H} \ldots \mathrm{O}=\mathrm{C}$ of the centrosymmetric dimer as contributing to the lower frequency $\mathrm{VN}-\mathrm{H}$ bands of reline's spectrum. Experimental support comes from matrix isolation studies of urea and acetamide, whose gas phase infrared spectra only have two sharp peaks above $3400 \mathrm{~cm}^{-1}$ for the isolated molecule. After annealing, a strong band in the $3200 \mathrm{~cm}^{-1}$ region arises from the bonded $\mathrm{N}-\mathrm{H}$ stretch of the cyclic dimers and trimers ${ }^{58,65,66}$. The radial distribution functions estimated by Zahn ${ }^{31}$ support the existence of centrosymmetric contacts between ureas in Reline since the $\mathrm{H}$ atoms which are cis to the $\mathrm{C}=\mathrm{O}$ bond have a strong preference for neighboring with oxygen atoms from another urea, while the trans $\mathrm{H}$ atoms prefer to interact with the chloride anion.

The hypothesis that a fraction of $\mathrm{N}-\mathrm{H}$ contacts is stronger in Reline may seem to contradict the previous assertion that urea deviates from planarity, a scenario usually associated with less hydrogen bonded environments. However, the formation of one or two strong hydrogen bonds, such as in the urea centrosymmetric dimer, does not guarantee planarity. For that to occur there must be $\mathrm{H}$ bond acceptors conveniently placed next to all four hydrogens of urea. Otherwise, the hydrogens not directly involved in hydrogen bonding will deviate even further from planarity ${ }^{67}$. Therefore, the existence of a sub-population of urea molecules involved in stronger hydrogen bonding is not in conflict with the overall deviation from planarity observed.

The centrosymmetric dimer motif is absent in crystalline urea, whose long chains are the most stable in the "head-to-tail" configuration, while for dimers, the most stable geometry is cyclic ${ }^{64}$. The formation of cyclic dimers frustrates crystallization by competing with the formation of "head-to-tail" chains, likely one the factors leading to Reline's pronounced deviation from ideality.

\subsubsection{The elusive vOH - a deuteration saga}

The location of choline's $\mathrm{vOH}$ mode in Reline is an important piece of the hydrogen bonding puzzle since it reflects the strength of the hydroxyl's interactions with chloride and urea. The $\mathrm{vOH}$ has been previously assigned by Perkins and colleagues ${ }^{17}$ to a shoulder at $3256 \mathrm{~cm}^{-1}$ in the FTIR spectrum of Reline although no evidence supporting this claim was provided. Based on the discrete ab-initio model, the relatively strong $\mathrm{OH}^{*} \mathrm{Cl}^{-}$and $\mathrm{OH}^{*} \mathrm{*} \mathrm{O}=\mathrm{C}$ contacts would give rise to stretching modes in the $3200 \mathrm{~cm}^{-1}$ region. Searching for further proof, we have attempted to isolate this vibrational mode, to no avail, due to fast isotopic exchange between hydroxyl and amine groups.

With a view to pulling apart the $\mathrm{vNH}$ and $\mathrm{VOH}$ vibrational bands, selective deuteration experiments were performed using urea-D4 and/or OD substituted choline chloride ([Ch]Cl-OD). Their FTIR spectra, taken immediately after preparation, are displayed in Fig. 11. The spectral changes, with increasing deuterium content, observed in the $\mathrm{OH} / \mathrm{NH}$ region mirror those in the $\mathrm{OD} / \mathrm{ND}$ region. At first glance, the broad band at $3316 \mathrm{~cm}^{-1}$ in Fig. 11 spectrum (b) (a 1:2 mixture of $[\mathrm{Ch}] \mathrm{ClOH}$ with Urea-D4) seemed to stem from $\mathrm{vOH}$. Repeated spectrum collection, for weeks after preparing the mixture, detected no changes. Therefore, either isotopic exchange is extremely slow, and the band at $3316 \mathrm{~cm}^{-1}$ has to be $\mathrm{vOH}$, or isotopic exchange is extremely fast and the band is a mixture of $\mathrm{vNH}$ and $\mathrm{VOH}$ contributions. By preparing a blend of (b) and (d), shown as spectrum (c), whose profile is clearly distinct from its original components, the fast exchange hypothesis was proven therefore, it is not possible to isolate $\mathrm{vOH}$. In mixture (d) there are 8 deuterium atoms in urea for each hydrogen in choline's $\mathrm{OH}$, so that after isotopic exchange there is $1 \mathrm{OH}: 8 \mathrm{NH}$ and the dominant substituted urea species is (ND2)CO(NDH). Therefore, the $\mathrm{VNH}$ contribution to the $3316 \mathrm{~cm}^{-1}$ band far exceeds that of $\mathrm{VOH}$ and discerning where $\mathrm{vOH}^{\prime} \mathrm{s}$ contribution lies proved to be a fruitless endeavor.

However, one may deduce that, upon forming the eutectic, the $\mathrm{vOH}$ band either maintains the same frequency as in $[\mathrm{Ch}] \mathrm{Cl}\left(3222 \mathrm{~cm}^{-1}\right)$ or slightly increases. In spectrum b), if $\mathrm{vOH}$ contributes weakly to the $3316 \mathrm{~cm}^{-1}$ band then it must have its center between 3200 and $3400 \mathrm{~cm}^{-1}$. Therefore, in Reline, the hydrogen bonds formed by choline's $\mathrm{OH}$ are of comparable strength or, possibly, slightly weaker than those found in the $[\mathrm{Ch}] \mathrm{Cl}$ crystal. The similar interaction scenario is in line with the average $\mathrm{OH}^{\prime \cdots} \mathrm{Cl}$ distance found 
in Hammond's ${ }^{16}$ neutron diffraction study, which is the same as in the $\mathrm{ChCl}$ crystal.

\section{Conclusions}

A blend of spectroscopic and computational tools has been used to probe the molecular conformation of Reline's constituents. Representing the full complexity and diversity of Reline's intermolecular interactions using a discrete cluster may remain an impossible task, yet achieving a satisfactory (albeit incomplete) representation at low computational cost is a goal within reach. Two choline chloride and four urea units is the minimum amount of building blocks needed to represent the most important interactions likely to exist in the eutectic mixture. The INS intensities of the internal vibrational modes of Reline, estimated from a discrete ab-initio calculation, are a satisfactory match to experiment. Little improvement is achieved by running a periodic calculation of the aggregate, save for the estimation of external modes, for which discrete calculations are wholly inadequate.

The low frequency region of Reline's inelastic neutron scattering spectrum shows a significant red-shift of choline's $\mathrm{CH}_{3}$ torsional modes compared to the choline chloride crystal. In the crystal, chloride anions sit at the top of three methyl groups, serving as linkers which hold choline cations together while hindering $\mathrm{CH}_{3}$ torsions. Upon forming the eutectic mixture the anion is displaced away from choline's headgroup, freeing up space around methyl groups and lowering their torsional barrier. The red-shift of choline's $\mathrm{CH}_{3}$ torsions is thus a fine illustration of the tetraalkylammonium salt's lattice disruption.

Overall, the choline cation skeletal structure is fairly conserved in Reline except for a small population whose NCCO backbone shifts into the trans conformation. Energetically inaccessible in the pure crystal, the presence of trans conformers in both Reline and aqueous solution denote a freer rotation of the $\mathrm{C}-\mathrm{C}$ bond in the liquid state. Still, the gauche conformer predominates and should be the geometry used to represent the choline cation in future abinitio calculations, a practice not always observed so far.

Urea undergoes drastic changes upon forming the eutectic, deviating from the planar (sp2) structure it prefers in the crystal to assume a non-planar shape, intermediate between that of the solid and the fully pyramidal (sp3) structure of the isolated molecule. Loss of planarity is a direct response to the disruption of urea's highly ordered and cooperative interactions in the crystal, relaxing into the fluctuating and flexible hydrogen bond network of Reline, an environment where a non-planar shape is more advantageous. The flexibility of urea in the mixture is attested by its broad $\mathrm{N}-\mathrm{H}$ stretching profile, denouncing a wide range of intermolecular contacts with varying strengths, from the stronger $\mathrm{N}-\mathrm{H} \ldots \mathrm{O}=\mathrm{C}$ bonds of the centrosymmetric dimer to the softer "head-to-tail" contacts. Likewise, choline's headgroup is involved in weaker interactions with chloride anions while the hydroxyl moiety interacts more strongly with $\mathrm{Cl}^{-}$.

Significantly stronger hydrogen bonds among Reline's components would lead to a stiffer network, with higher melting point, while much weaker interactions would hinder mixing. Eutectic behavior emerges when "Goldilocks" conditions are achieved and a perfect balance of opposite effects allows two crystalline components to mix, while preventing them from settling into a co-crystal, at room temperature.

\section{Acknowledgements}

This work was developed within the scope of the project CICECOAveiro Institute of Materials, POCI-01-0145-FEDER-007679 (FCT Ref. UID /CTM /50011/2013) and project DEEPBIOREFINERY (PTDC/AGRTEC/1191/2014), financed by national funds through the FCT/MEC and when appropriate co-financed by FEDER under the PT2020 Partnership Agreement The STFC Rutherford Appleton Laboratory is thanked for access to neutron beam facilities. CASTEP calculations were made possible due to the computing resources provided by STFC Scientific Computing Department's SCARF cluster.

\section{References}

1. Q. H. Zhang, K. D. Vigier, S. Royer and F. Jerome, Chemical Society Reviews, 2012, 41, 7108-7146.

2. D. Carriazo, M. C. Serrano, M. C. Gutierrez, M. L. Ferrer and F. del Monte, Chemical Society Reviews, 2012, 41, 4996-5014.

3. M. Francisco, A. van den Bruinhorst and M. C. Kroon, Angewandte Chemie-International Edition, 2013, 52, 3074-3085.

4. B. K. Tang and K. H. Row, Monatshefte Fur Chemie, 2013, $144,1427-1454$.

5. E. L. Smith, A. P. Abbott and K. S. Ryder, Chemical Reviews, 2014, 114, 11060-11082.

6. D. V. Wagle, H. Zhao and G. A. Baker, Accounts of Chemical Research, 2014, 47, 2299-2308.

7. G. Garcia, S. Aparicio, R. Ullah and M. Atilhan, Energy Fuels, 2015, 29, 2616-2644.

8. A. P. Abbott, G. Capper, D. L. Davies, R. K. Rasheed and V. Tambyrajah, Chemical Communications, 2003, 70-71. 
9. X. Q. Meng, K. Ballerat-Busserolles, P. Husson and J. M. Andanson, New Journal of Chemistry, 2016, 40, 44924499.

10. G. Garcia, M. Atilhan and S. Aparicio, Chemical Physics Letters, 2015, 634, 151-155.

11. S. Zahn, B. Kirchner and D. Mollenhauer, Chemphyschem, 2016, 17, 3354-3358.

12. A. Abbott, D. Davies, G. Capper, R. Rasheed and V. Tambyrajah, Scionix Limited, London (GB), U.S.A., 2007, ch. US007183433B2.

13. S. Saito, M. Lee and W. Y. Wen, Journal of the American Chemical Society, 1966, 88, 5107-5112;.

14. Q. Li and T. C. W. Mak, Acta Crystallographica Section BStructural Science, 1998, 54, 180-192.

$15 . \quad$ C. R. Ashworth, R. P. Matthews, T. Welton and P. A. Hunt, Physical Chemistry Chemical Physics, 2016, 18, 1814518160.

16. O. S. Hammond, D. T. Bowron and K. J. Edler, Green Chemistry, 2016, 18, 2736-2744.

17. S. L. Perkins, P. Painter and C. M. Colina, Journal of Physical Chemistry B, 2013, 117, 10250-10260.

18. S. L. Perkins, P. Painter and C. M. Colina, Journal of Chemical and Engineering Data, 2014, 59, 3652-3662.

19. D. Shah and F. S. Mjalli, Physical Chemistry Chemical Physics, 2014, 16, 23900-23907.

20. D. V. Wagle, G. A. Baker and E. Mamontov, Journal of Physical Chemistry Letters, 2015, 6, 2924-2928.

21. D. V. Wagle, C. A. Deakyne and G. A. Baker, Journal of Physical Chemistry B, 2016, 120, 6739-6746.

22. D. Y. Yue, Y. Z. Jia, Y. Yao, J. H. Sun and Y. Jing, Electrochimica Acta, 2012, 65, 30-36.

23. S. W. Zhu, H. P. Li, W. S. Zhu, W. Jiang, C. Wang, P. W. Wu, Q. Zhang and H. M. Li, Journal of Molecular Graphics and Modelling, 2016, 68, 158-175.

24. C. D'Agostino, R. C. Harris, A. P. Abbott, L. F. Gladden and M. D. Mantle, Physical Chemistry Chemical Physics, 2011, 13, 21383-21391.

25. H. Sun, Y. Li, X. Wu and G. H. Li, Journal of Molecular Modeling, 2013, 19, 2433-2441.

26.

C. S. Yuan, K. K. Chu, H. N. Li, L. Su, K. Yang, Y. Q. Wang and X. D. Li, Chemical Physics Letters, 2016, 661, 240-245.
27. A. Pandey and S. Pandey, Journal of Physical Chemistry B, 2014, 118, 14652-14661.

28. C. Zhang, Y. Z. Jia, Y. Jing, H. Y. Wang and K. Hong, Journal of Molecular Modeling, 2014, 20.

29. H. Monhemi, M. R. Housaindokht, A. A. MoosaviMovahedi and M. R. Bozorgmehr, Physical Chemistry Chemical Physics, 2014, 16, 14882-14893.

30. S. Kaur, A. Gupta and H. K. Kashyap, Journal of Physical Chemistry B, 2016, 120, 6712-6720.

31. S. Zahn, Physical Chemistry Chemical Physics, 2017, 19, 4041-4047.

32. R. Stefanovic, M. Ludwig, G. B. Webber, R. Atkin and A. J. Page, Physical Chemistry Chemical Physics, 19, 3297-3306.

33. S. F. Parker, D. Lennon and P. W. Albers, Applied Spectroscopy, 2011, 65, 1325-1341.

34. D. Colognesi, M. Celli, F. Cilloco, R. J. Newport, S. F. Parker, V. Rossi-Albertini, F. Sacchetti, J. Tomkinson and M. Zoppi, Applied Physics A, 2002, 74, S64-S66.

35. S. F. Parker, F. Fernandez-Alonso, A. J. Ramirez-Cuesta, J. Tomkinson, S. Rudic, R. S. Pinna, G. Gorini and J. F. Castanon, Journal of Physics Conference Series, 2014, 554, 012003.

36. S. F. Parker, A. J. Ramirez-Cuesta, P. W. Albers and D. Lennon, Journal of Physics Conference Series, 2014, 554, 012004.

37. B. Bozzini, B. Busson, C. Humbert, C. Mele and A. Tadjeddine, Electrochimica Acta, 2016, 218, 208-215.

38.

S. J. Clark, M. D. Segall, C. J. Pickard, P. J. Hasnip, M. J. Probert, K. Refson and M. C. Payne, Zeitschrift Fur Kristallographie, 2005, 220, 567-570.

39. M. R. Johnson, K. Parlinski, I. Natkaniec and B. S. Hudson, Chemical Physics, 2003, 291, 53-60.

40. ISIS-RAL-STFC, TOSCA Database, http://wwwisis2.isis.rl.ac.uk/INSdatabase/Theindex.asp.

41. G. W. T. M. J. Frisch, H. B. Schlegel, G. E. Scuseria, M. A. Robb, J. R. Cheeseman, G. Scalmani, V. Barone, G. A. Petersson, H. Nakatsuji, X. Li, M. Caricato, A. Marenich, J. Bloino, B. G. Janesko, R. Gomperts, B. Mennucci, H. P. Hratchian, J. V. Ortiz, A. F. Izmaylov, J. L. Sonnenberg, D. Williams-Young, F. Ding, F. Lipparini, F. Egidi, J. Goings, B. Peng, A. Petrone, T. Henderson, D. Ranasinghe, V. G. Zakrzewski, J. Gao, N. Rega, G. Zheng, W. Liang, M. Hada, M. Ehara, K. Toyota, R. Fukuda, J. Hasegawa, M. Ishida, T. 
Nakajima, Y. Honda, O. Kitao, H. Nakai, T. Vreven, K. Throssell, J. A. Montgomery, Jr., J. E. Peralta, F. Ogliaro, M. Bearpark, J. J. Heyd, E. Brothers, K. N. Kudin, V. N. Staroverov, T. Keith, R. Kobayashi, J. Normand, K. Raghavachari, A. Rendell, J. C. Burant, S. S. Iyengar, J. Tomasi, M. Cossi, J. M. Millam, M. Klene, C. Adamo, R. Cammi, J. W. Ochterski, R. L. Martin, K. Morokuma, O. Farkas, J. B. Foresman, D. J. Fox, Gaussian, Inc., Wallingford CT, 2016.

42. A. J. Ramirez-Cuesta, Computer Physics Communications, 2004, 157, 226-238.

43. NIST, Precomputed vibrational scaling factors, http://cccbdb.nist.gov/vibscalejust.asp.

44. M. Tarini, P. Cignoni and C. Montani, leee Transactions on Visualization and Computer Graphics, 2006, 12, 12371244.

45. K. Refson, P. R. Tulip and S. J. Clark, Physical Review B, 2006, 73.

46. J. P. Perdew, K. Burke and M. Ernzerhof, Physical Review Letters, 1996, 77, 3865-3868.

47. V. Milman, A. Perlov, K. Refson, S. J. Clark, J. Gavartin and B. Winkler, Journal of Physics-Condensed Matter, 2009, 21.

48. A. Pawlukojc and L. Hetmanczyk, Chemical Physics, 2014, 445, 31-37.

49. A. Keuleers, H. O. Desseyn, B. Rousseau and C. Van Alsenoy, Journal of Physical Chemistry A, 1999, 103, 46214630.

50. P. W. Albers, J. Glenneberg, K. Refson and S. F. Parker, The Journal of Chemical Physics, 140, 164504.

51. P. C. H. Mitchell, S. F. Parker, A. J. Ramirez-Cuesta and J. Tomkinson, in Vibrational Spectroscopy with Neutrons: With Applications in Chemistry, Biology, Materials Science and Catalysis, ed. P. C. H. Mitchell, World Scientific Co. Pte. Ltd., Singapore, 2005, vol. 3, ch. 8, pp. 374-378.

52.

C. I. Ratcliffe and T. C. Waddington, Journal of the Chemical Society, Faraday Transactions 2, 1976, 72, 19351956.

53. J. Eckert, T. D. Sewell, J. D. Kress, E. M. Kober, L. L. Wang and G. Olah, Journal of Physical Chemistry A, 2004, 108, 11369-11374.

54.
J. M. Newsam, T. O. Brun, F. Trouw, L. E. Iton and L. A.

Curtiss, in Novel Materials in Heterogeneous Catalysis,
American Chemical Society, 1990, vol. 437, ch. 3, pp. 2537.

55. H. Akutsu, Biochemistry, 1981, 20, 7359-7366.

56. P. Vaughan and J. Donohue, Acta Crystallographica, 1952, $5,530-535$.

57. J. I. Mujika, J. M. Matxain, L. A. Eriksson and X. Lopez, Chemistry-a European Journal, 2006, 12, 7215-7224.

58. S. T. King, Spectrochimica Acta Part A: Molecular Spectroscopy, 1972, A 28, 165-175;.

59. J. C. Dobrowolski, R. Kolos, J. Sadlej and A. P. Mazurek, Vibrational Spectroscopy, 2002, 29, 261-282.

60. B. Rousseau, C. Van Alsenoy, R. Keuleers and H. O. Desseyn, Journal of Physical Chemistry A, 1998, 102, 65406548.

61. P. Hobza and V. Spirko, Physical Chemistry Chemical Physics, 2003, 5, 1290-1294.

62. M. D. Esrafili, J. Beheshtian and N. L. Hadipour, International Journal of Quantum Chemistry, 2011, 111, 3184-3195.

63. NIST, Urea Hydrochloride IR Spectrum, http://webbook.nist.gov/cgi/cbook.cgi?ID=C506898\&Mas $\mathrm{k}=80 \# \mathrm{IR}-\mathrm{Spec}$

64. A. Masunov and J. J. Dannenberg, The Journal of Physical Chemistry B, 2000, 104, 806-810.

65. J. Langer, B. Schrader, V. Bastian and E. Jacob, Fresenius' Journal of Analytical Chemistry, 1995, 352, 489-495.

66. M. Spoliti, G. Perrone, L. Bencivenni, A. Pieretti, A. Grandi and F. Ramondo, Journal of Molecular StructureTheochem, 2005, 756, 113-126.

67. J. A. Platts, H. Maarof, K. D. M. Harris, G. K. Lim and D. J. Willock, Physical Chemistry Chemical Physics, 2012, 14, 11944-11952. 


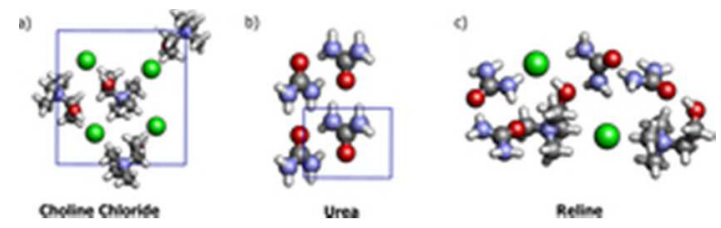

Figure 1. Molecular representation of the crystal lattices of a) choline chloride and b) urea along with c) the optimized geometry of Reline's model. [Ch]Cl's unit cell is viewed down the c axis while urea's is shown along the $b$ axis. The .cif files for urea and choline chloride's crystal structures are available at the CCDC database with refcodes UREAXX25 and CHOCHL01, respectively.

$22 \times 6 \mathrm{~mm}(300 \times 300 \mathrm{DPI})$ 


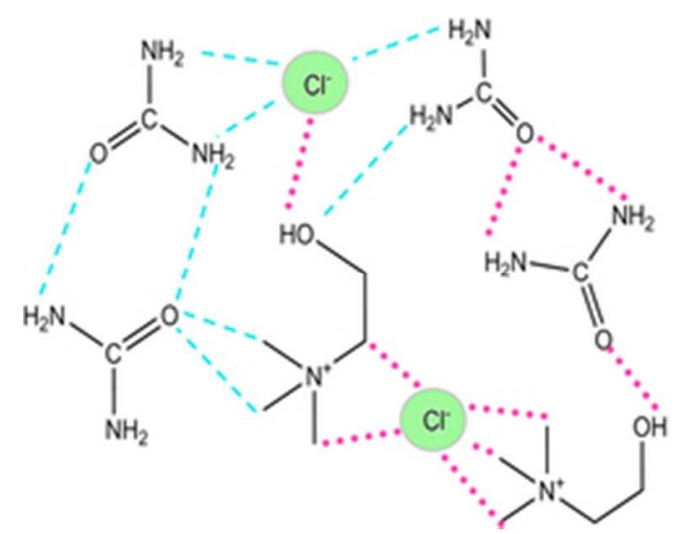

Figure 2. Schematic representation of the $2[\mathrm{Ch}] \mathrm{Cl}: 4 U$ rea cluster, highlighting the most relevant intermolecular contacts present in Reline (dashed lines) and those already present in the pure solids (dotted lines).

$20 \times 16 \mathrm{~mm}(300 \times 300$ DPI $)$ 


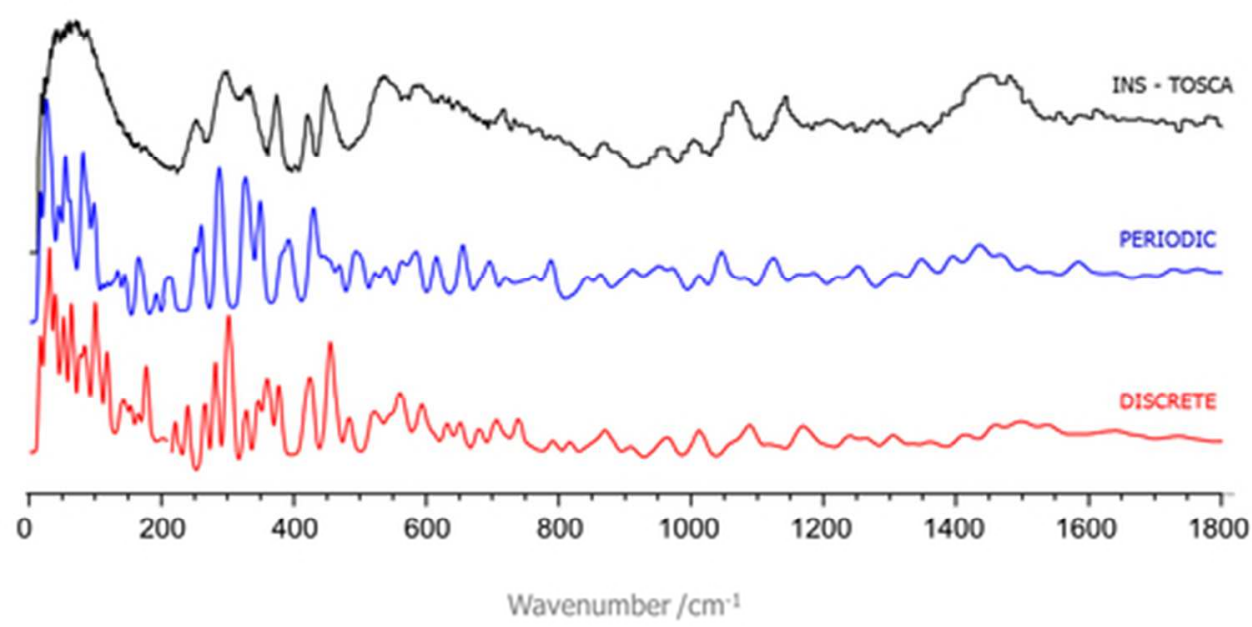

Reline's INS spectra, recorded using TOSCA (top) are compared with those estimated in silico by a periodic (middle) and a discrete (bottom) calculation.

$41 \times 23 \mathrm{~mm}(300 \times 300$ DPI $)$ 


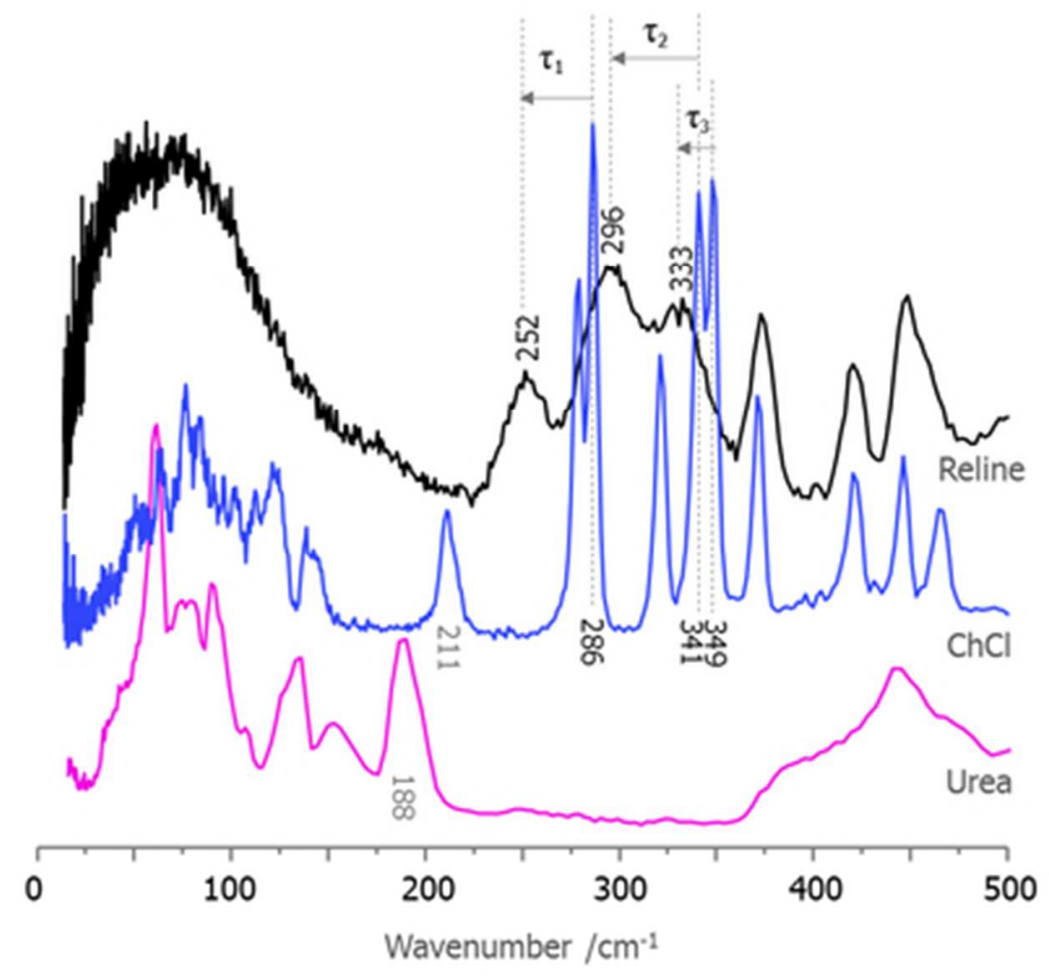

Figure 4. Low frequency region of the INS spectra of Reline (top), choline chloride (middle) and urea (bottom), collected using the TOSCA instrument at $20 \mathrm{~K}$.

$37 \times 32 \mathrm{~mm}(300 \times 300$ DPI $)$ 


\section{$v_{\mathrm{s} 1} \mathrm{CN}$ gauche}

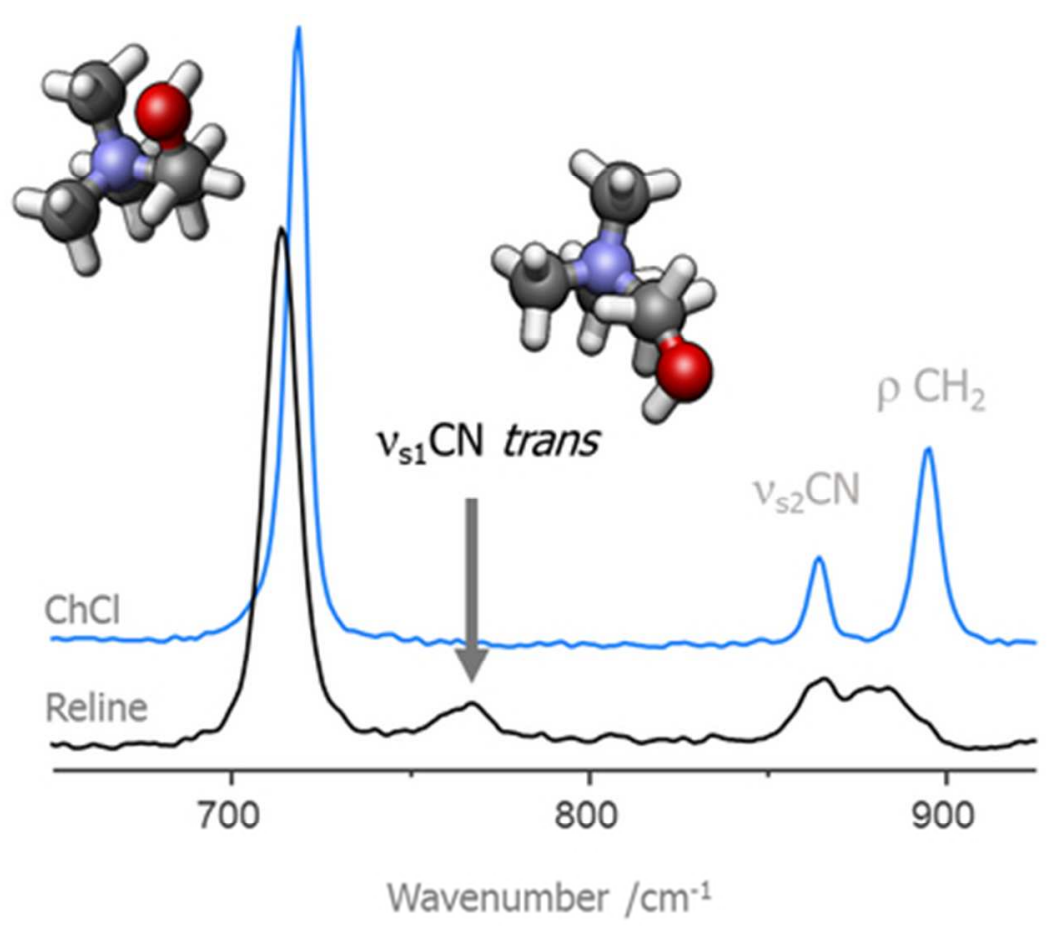

Figure 5. Raman spectra of choline chloride and reline in the symmetric VCN region. The stretching bands arising from choline cations in the gauche and trans conformation are highlighted along with molecular models of the two isomers.

$35 \times 36 \mathrm{~mm}(300 \times 300 \mathrm{DPI})$ 


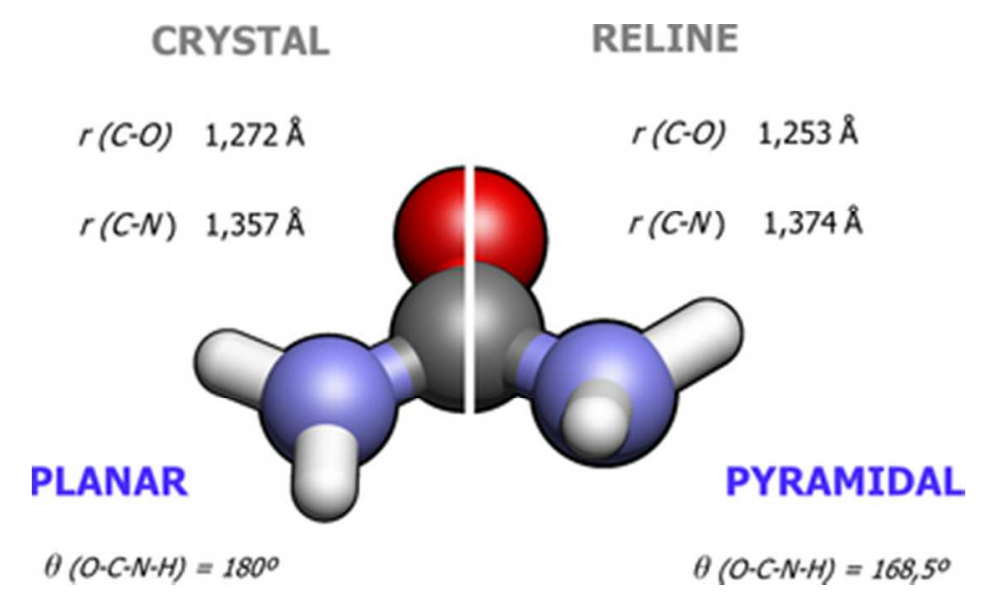

Figure 6. Comparison of urea's planar (left) and pyramidal (right) architectures. The C-N and C-O bond lengths ( $r$ ) displayed, as well as the torsion angles $(\theta)$, result from CASTEP calculations on urea's crystal and Reline's model aggregate. In Reline's model each urea molecule has different structural parameters so that the average value is shown. The average calculated $\theta(\mathrm{O}-\mathrm{C}-\mathrm{N}-\mathrm{H})$ for the isolated urea molecule in the fully pyramidal configuration is $160^{\circ}$.

$30 \times 18 \mathrm{~mm}(300 \times 300 \mathrm{DPI})$ 


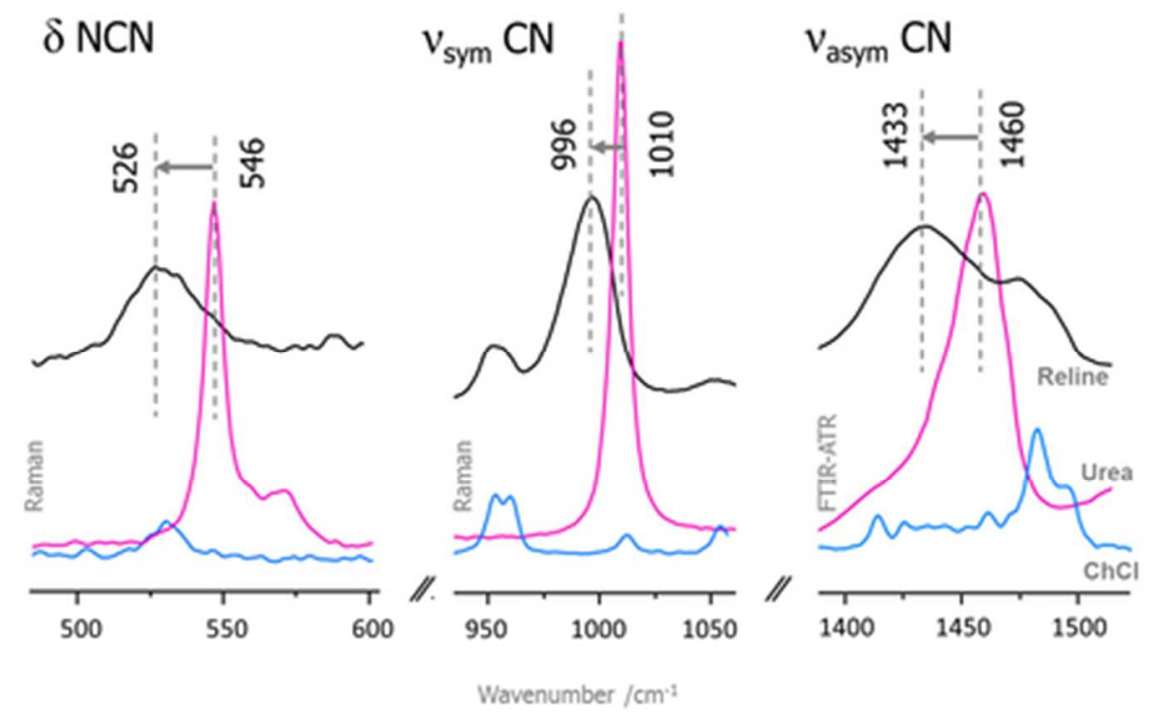

Figure 7. Selected regions of the Raman and infrared spectra of Reline (top) and its pure components (bottom) illustrating the red-shift of urea's $\mathrm{C}-\mathrm{N}$ vibrations when going from the planar structure found in the crystal to the non-planar shape it adopts in reline.

$39 \times 24 \mathrm{~mm}(300 \times 300$ DPI $)$ 

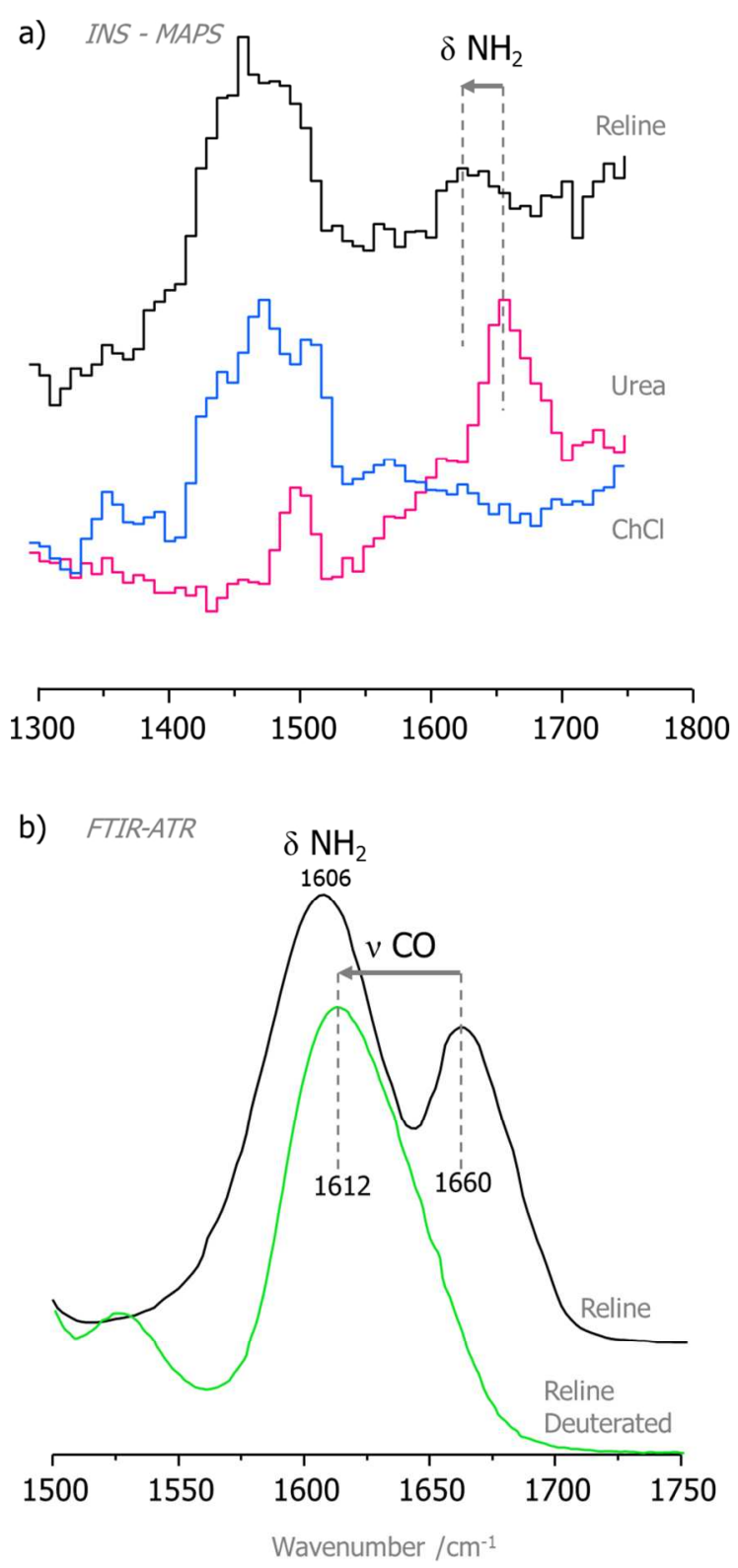

Figure 8. a) INS spectra of Reline (top), choline chloride and urea (bottom), recorded using MAPS, with an incident energy of $2016 \mathrm{~cm}-1(0 \leq \mathrm{Q} \leq 9 \AA-1)$; b) FTIR-ATR spectrum of reline and its partially deuterated version, prepared with urea-D4.

$80 \times 173 \mathrm{~mm}(300 \times 300 \mathrm{DPI})$ 


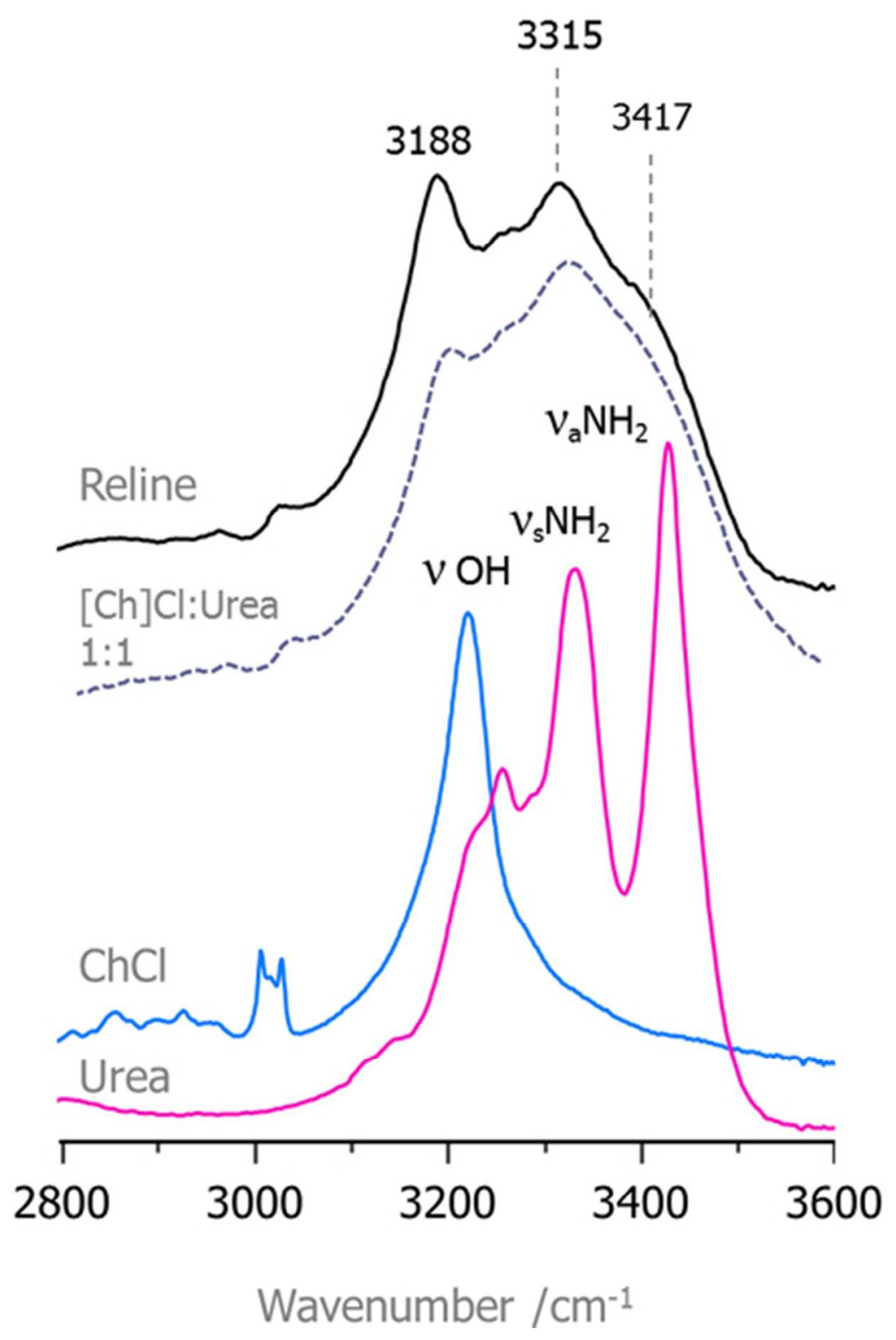

Figure 9. FTIR-ATR spectra in the stretching region of Reline (1C:2U) (top), choline chloride (middle) and urea's (bottom). The dashed line corresponds to the $1: 1$ liquid mixture $(1 \mathrm{C}: 1 \mathrm{U})$ and stress the contribution of urea to the band profile.

$42 \times 56 \mathrm{~mm}(300 \times 300$ DPI $)$ 


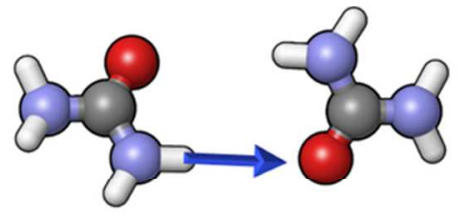

3042

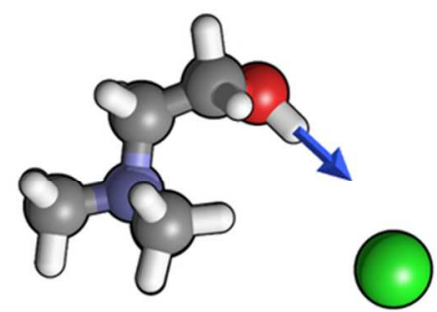

3188
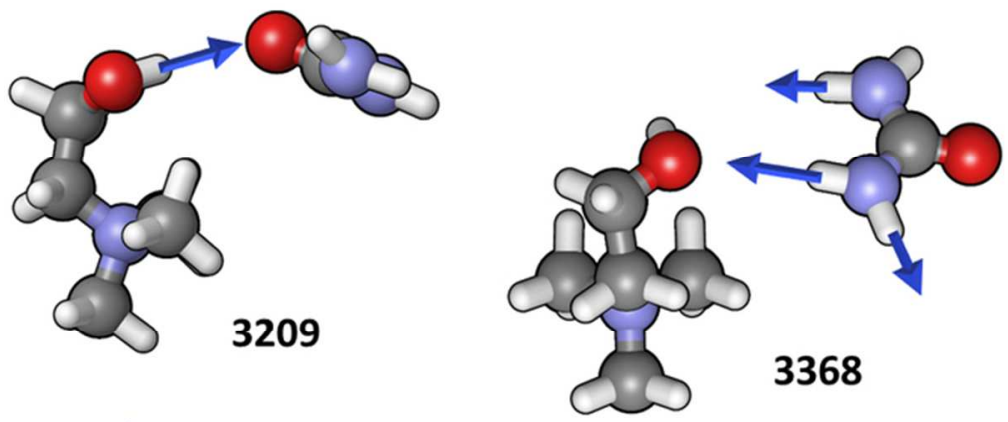

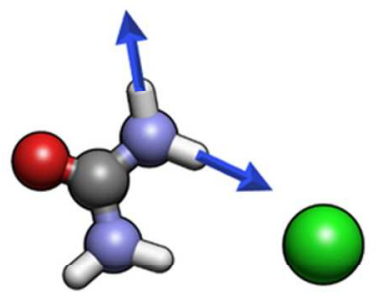

3335

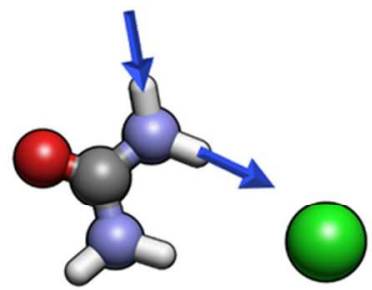

3466

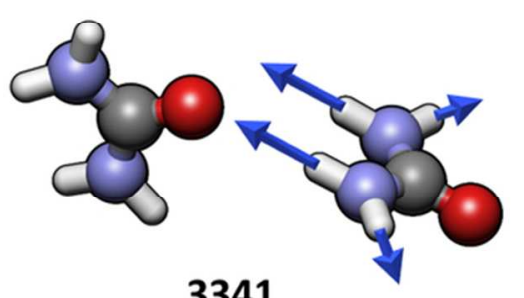

3341
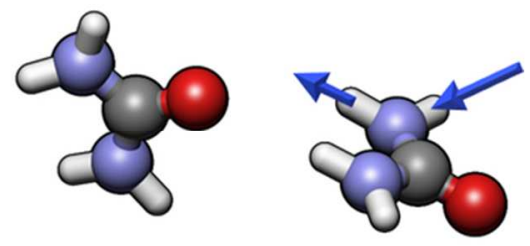

3576

Normal mode displacement vectors and harmonic frequencies for the $\mathrm{NH}$ and $\mathrm{OH}$ stretching modes of selected pairs, as calculated using the cluster model. From top to bottom, increasing wavenumber: $\mathrm{vNH}$ (centrosymmetric dimer); $\mathrm{vOH}$ (Choline...Cl and Choline...Urea); symmetric vNH $\mathrm{NH}_{2}$ (Urea...Choline, Urea... Cl and Urea...Urea), asymmetric $\mathrm{vNH}_{2}$ (Urea...Cl and Urea...Urea). 

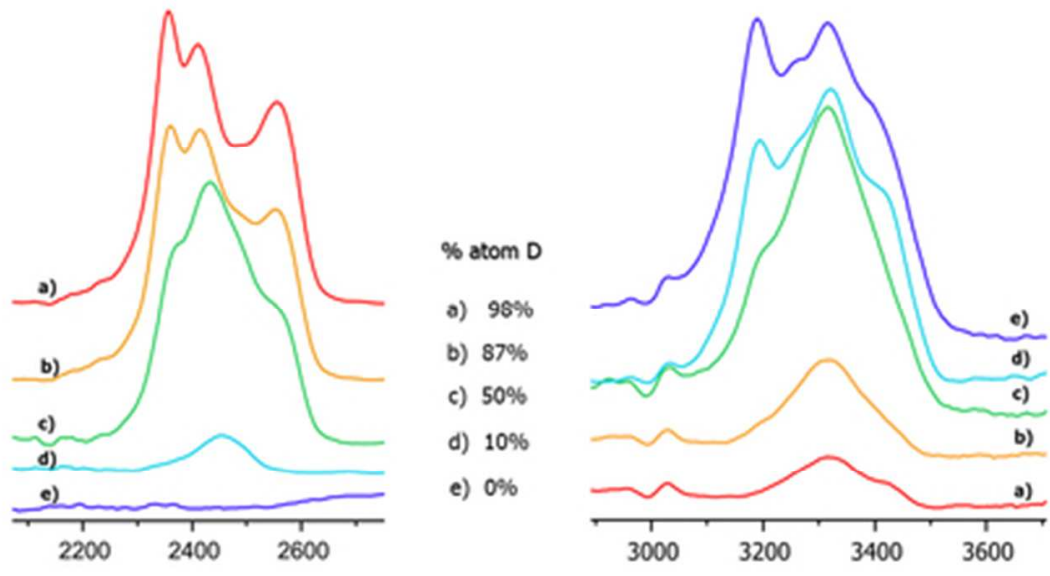

Wavenumber $/ \mathrm{cm}:$

Figure 11. The VND and VOD region (left) and the $\mathrm{VNH}$ and $\mathrm{VOH}$ region (righ) of Reline's FTIR-ATR spectrum for mixtures with increasing deuterium content ( $\%$ atom $D)$.

$35 \times 20 \mathrm{~mm}(300 \times 300 \mathrm{DPI})$ 
Goldilocks conditions of hydrogen bond strength on the basis of deep eutectic behaviour

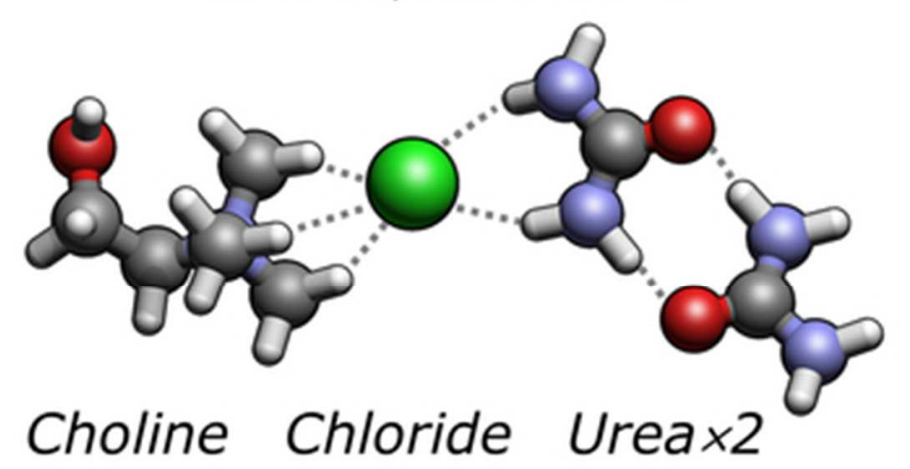

$29 \times 18 \mathrm{~mm}(300 \times 300$ DPI $)$ 


\section{Inelastic Neutron Scattering study of Reline: \\ shedding light on the hydrogen bonding network of deep eutectic solvents}

\section{Supporting Material}

C. Araujo *a, J. A. P. Coutinho ${ }^{a}$, M. M. Nolasco ${ }^{a}$, S.F. Parker ${ }^{b}$, P. J. A. RibeiroClaro *a,

S. Rudić ${ }^{b}$, B. I. G. Soares ${ }^{a}$, P. D. Vaz ${ }^{b, c}$

${ }^{a}$ CICECO - Aveiro Institute of Materials, Department of Chemistry, University of Aveiro, 3810193 Aveiro, Portugal

${ }^{b}$ ISIS Neutron \& Muon Source, Rutherford Appleton Laboratory, Chilton, Didcot, Oxfordshire OX11 0QX, UK

c CQB, Departamento de Química e Bioquímica, Faculdade de Ciências da Universidade de Lisboa, 1749-016 Lisboa, Portugal.

$*_{\bowtie}$ prc@ua.pt ; catarina.araujo@ua.pt 
Figure S1. Optimized geometry of the aggregate used to model Reline, with dotted lines evidencing hydrogen bonding sites. This image was rendered using the ChemCraft program (http://www.chemcraftprog.com).

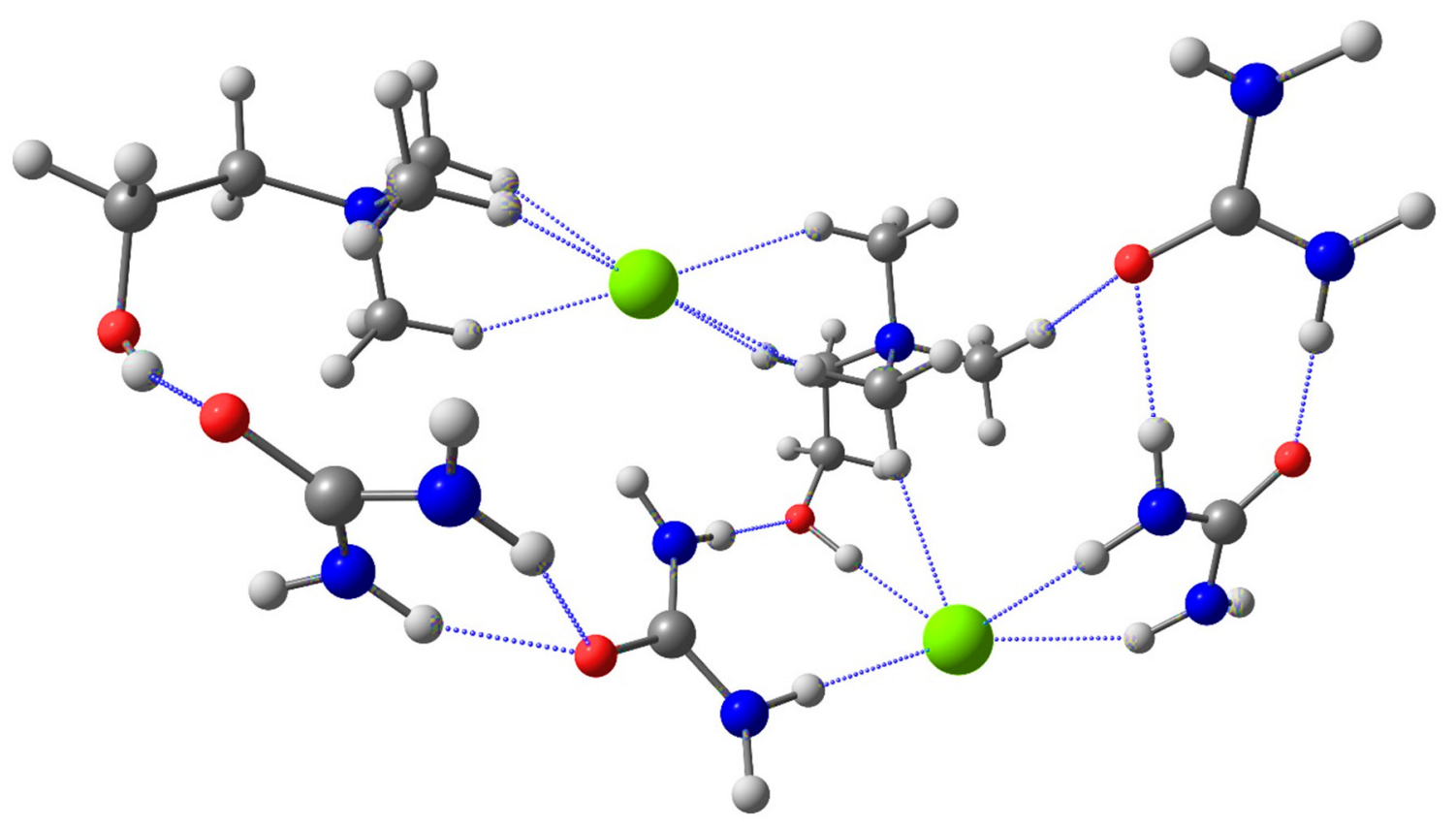

Table S1. Coordinates of reline's model optimized geometry

$\begin{array}{lrrr}\text { N } & 2.261656000 & -1.120176000 & 1.554849000 \\ \mathrm{C} & 1.884686000 & -2.570277000 & 1.381075000 \\ \mathrm{H} & 0.795557000 & -2.631545000 & 1.318832000 \\ \mathrm{H} & 2.354022000 & -2.929988000 & 0.464392000 \\ \mathrm{H} & 2.254961000 & -3.133264000 & 2.240184000 \\ \mathrm{C} & 1.782484000 & -0.375613000 & 0.326072000 \\ \mathrm{H} & 0.695970000 & -0.461676000 & 0.288043000 \\ \mathrm{H} & 2.094478000 & 0.664398000 & 0.398277000 \\ \mathrm{H} & 2.244938000 & -0.853027000 & -0.538266000 \\ \mathrm{C} & 3.757755000 & -1.008761000 & 1.654905000 \\ \mathrm{H} & 4.039325000 & 0.043510000 & 1.663160000 \\ \mathrm{H} & 4.084301000 & -1.502591000 & 2.572665000 \\ \mathrm{H} & 4.191252000 & -1.493624000 & 0.779641000 \\ \mathrm{C} & 1.572938000 & -0.617532000 & 2.823958000 \\ \mathrm{C} & 1.937739000 & 0.779489000 & 3.329107000 \\ \mathrm{H} & 1.838213000 & -1.342620000 & 3.600849000 \\ \mathrm{H} & 0.498739000 & -0.691857000 & 2.626709000 \\ \mathrm{H} & 1.498365000 & 0.832744000 & 4.335020000 \\ \mathrm{H} & 3.021125000 & 0.896548000 & 3.453251000 \\ \mathrm{O} & 1.405899000 & 1.835013000 & 2.558679000 \\ \mathrm{H} & 2.129833000 & 2.286899000 & 2.053083000 \\ \mathrm{Cl} & 3.421576000 & 3.016832000 & 0.643392000 \\ \mathrm{C} & 6.243184000 & 0.805734000 & -0.758686000 \\ \mathrm{O} & 7.062892000 & -0.133275000 & -0.859430000 \\ \mathrm{~N} & 4.979846000 & 0.738012000 & -1.268544000 \\ \mathrm{H} & 4.635185000 & -0.190376000 & -1.491425000\end{array}$




\begin{tabular}{lrrr} 
H & 4.303894000 & 1.438336000 & -0.970757000 \\
$\mathrm{~N}$ & 6.583449000 & 1.990368000 & -0.167703000 \\
$\mathrm{H}$ & 7.471797000 & 2.005583000 & 0.307728000 \\
$\mathrm{H}$ & 5.851532000 & 2.620825000 & 0.149406000 \\
$\mathrm{C}$ & 5.021727000 & -2.944975000 & -1.944157000 \\
$\mathrm{O}$ & 4.135155000 & -2.239474000 & -1.422049000 \\
$\mathrm{~N}$ & 4.692266000 & -4.164161000 & -2.514733000 \\
$\mathrm{H}$ & 3.706577000 & -4.279897000 & -2.699431000 \\
$\mathrm{H}$ & 5.310530000 & -4.575694000 & -3.199152000 \\
$\mathrm{~N}$ & 6.326711000 & -2.600434000 & -1.944599000 \\
$\mathrm{H}$ & 6.615429000 & -1.691375000 & -1.538881000 \\
$\mathrm{H}$ & 7.027562000 & -3.193988000 & -2.359306000 \\
$\mathrm{~N}$ & -5.377316000 & -1.744640000 & 0.679953000 \\
$\mathrm{C}$ & -5.069964000 & -0.386299000 & 1.276096000 \\
$\mathrm{C}$ & -4.594471000 & -1.916891000 & -0.599944000 \\
$\mathrm{C}$ & -4.912416000 & -2.790485000 & 1.662951000 \\
$\mathrm{C}$ & -6.873328000 & -1.922510000 & 0.450519000 \\
$\mathrm{C}$ & -7.503516000 & -1.171665000 & -0.728148000 \\
$\mathrm{O}$ & -7.471576000 & 0.227514000 & -0.594277000 \\
$\mathrm{H}$ & -5.610560000 & -0.304522000 & 2.220496000 \\
$\mathrm{H}$ & -5.410547000 & 0.383029000 & 0.590441000 \\
$\mathrm{H}$ & -3.990923000 & -0.339928000 & 1.439295000 \\
$\mathrm{H}$ & -3.533050000 & -1.867788000 & -0.341045000 \\
$\mathrm{H}$ & -4.847054000 & -2.890306000 & -1.026170000 \\
$\mathrm{H}$ & -4.859636000 & -1.117384000 & -1.291255000 \\
$\mathrm{H}$ & -3.847382000 & -2.624502000 & 1.850713000 \\
$\mathrm{H}$ & -5.076916000 & -3.777841000 & 1.228019000 \\
$\mathrm{H}$ & -5.492117000 & -2.685790000 & 2.581793000 \\
$\mathrm{H}$ & -7.357073000 & -1.623749000 & 1.384321000 \\
$\mathrm{H}$ & -2.529147000 & 1.836394000 & -2.433402000 \\
$\mathrm{H}$ & -7.032036000 & -2.995940000 & 0.303723000 \\
$\mathrm{H}$ & -7.053599000 & -1.492986000 & -1.675220000 \\
$\mathrm{H}$ & -8.549894000 & -1.511721000 & -0.744747000 \\
$\mathrm{H}$ & -6.852855000 & 0.592652000 & -1.276847000 \\
$\mathrm{Cl}$ & -1.643071000 & -1.393876000 & 1.291338000 \\
$\mathrm{C}$ & -0.785317000 & 3.036077000 & -0.409125000 \\
$\mathrm{~N}$ & -0.784729000 & 2.094931000 & 0.565018000 \\
$\mathrm{H}$ & -1.461782000 & 1.344859000 & 0.532135000 \\
$\mathrm{H}$ & -0.062117000 & 2.036145000 & 1.278743000 \\
$\mathrm{~N}$ & 0.252862000 & 3.920205000 & -0.418688000 \\
$\mathrm{H}$ & 0.271973000 & 4.541579000 & -1.212757000 \\
$\mathrm{H}$ & 1.153285000 & 3.701912000 & 0.006692000 \\
- & -4.713879000 & 3.126557000 & -1.253496000 \\
\hline & -4.522179000 & 2.503550000 & -1.118465000 \\
$\mathrm{H}$ & -3.663673000 & 3.034895000 & -0.970730000 \\
\hline
\end{tabular}


Table S2. Assignment of reline's vibrational modes. The first three columns list the vibrational frequency in $\mathrm{cm}-1$.

\begin{tabular}{|c|c|c|c|c|}
\hline $\begin{array}{l}\text { Coline } \\
\text { Chloride }\end{array}$ & Urea & Reline & Obs. & Technique \\
\hline 50 & 62 & 48 & Lattice mode & INS \\
\hline 64 & 74 & & Lattice mode & INS \\
\hline 77 & 80 & 72 & Lattice mode & INS \\
\hline 84 & 90 & & Lattice mode & INS \\
\hline \multirow[t]{2}{*}{112} & 107 & & Lattice mode & INS \\
\hline & 126 & & Lattice mode & INS \\
\hline 123 & 135 & & Lattice mode & INS \\
\hline \multirow[t]{2}{*}{139} & 152 & & Lattice mode & INS \\
\hline & 188 & $178 ?$ & Lattice mode & INS \\
\hline 211 & & $178 ?$ & $\tau \mathrm{CC}+v \mathrm{OH} \ldots \mathrm{Cl} / v \mathrm{OH} \ldots \mathrm{O}=\mathrm{C}$ & INS \\
\hline 279 & & shldr & $\delta \mathrm{NCC}$ & INS \\
\hline 286 & & 252 & $\tau \mathrm{CH}_{3}$ & INS \\
\hline 321 & & shlor & $\rho \mathrm{N}\left(\mathrm{CH}_{3}\right)_{3}$ & INS \\
\hline 341 & & 296 & Mainly $\left(\tau \mathrm{CH}_{3}\right)_{\mathrm{Ch}}$ small cont of $\left(\omega_{\mathrm{as}} \mathrm{NH}_{2}\right)_{u}$ & INS \\
\hline 349 & & 333 & $\tau \mathrm{CH}_{3}$ & INS \\
\hline 371 & & 373 & $\rho \mathrm{N}\left(\mathrm{CH}_{3}\right)_{3}$ & INS \\
\hline 421 & & 421 & $\delta \mathrm{N}\left(\mathrm{CH}_{3}\right)_{3}$ & INS \\
\hline 447,466 & 443 & 448 & $\left(\delta \mathrm{N}\left(\mathrm{CH}_{3}\right)_{3}\right)_{\mathrm{Ch}}$ small cont of $\left(\omega_{\mathrm{s}} \mathrm{NH}_{2}\right)_{\mathrm{u}}$ & INS \\
\hline \multirow[t]{2}{*}{532} & 546 & 526 & $(\delta \mathrm{NCN})_{\cup}$, small cont of $(\delta \mathrm{NCC} / \mathrm{CCO})_{\mathrm{Ch}}$ & Raman \\
\hline & 588,618 & 587 & $\tau_{\mathrm{as}} \mathrm{NH}_{2}$ small cont of $\delta \mathrm{CO}$ & INS \\
\hline 623 & & $?$ & $\tau \mathrm{OH}$ & INS \\
\hline \multirow[t]{3}{*}{719} & & 714 & $v_{s}(1) \mathrm{CN}$ (Ch gauche) & Raman \\
\hline & & 769 & $v_{\mathrm{s}}(1) \mathrm{CN}(\mathrm{Ch}$ trans) & Raman \\
\hline & 787 & 787 & $\pi \mathrm{CO}$ & FTIR \\
\hline 864 & & 866 & $v_{s}(2) C N$ & Raman \\
\hline 895 & & 884 shldr & $\rho \mathrm{CH}_{2}$ & Raman \\
\hline \multirow[t]{2}{*}{953,960} & & 958 & $v_{\text {as }}(3,4) \mathrm{CN}$ & Raman \\
\hline & 1010 & 997 & $v_{s} \mathrm{CN}$ & Raman \\
\hline 1016 & 1017 & 1002 & $\rho_{\mathrm{as}} \mathrm{NH}_{2}, \rho \mathrm{CH}_{3}, \rho \mathrm{CH}_{2}, \delta \mathrm{COH}$ & INS \\
\hline 1060, 1081 & & 1066 & $\rho \mathrm{CH}_{3}, \rho \mathrm{CH}_{2}, \delta \mathrm{COH}+v \mathrm{CC}$ & INS \\
\hline 1151 & 1158 & 1140 & $\left(\rho_{s} \mathrm{NH}_{2}\right)_{u}+\left(\rho \mathrm{CH}_{3}+v \mathrm{CO}\right)_{\mathrm{Ch}}$ & INS \\
\hline 1217 & & 1205 & $\rho \mathrm{CH}_{3}$ & INS \\
\hline 1285 & & 1279 & $\rho \mathrm{CH}_{3}$ & INS \\
\hline 1344 & & 1344 & $\omega \mathrm{CH}_{2}+\delta \mathrm{COH}$ & INS \\
\hline \multirow[t]{2}{*}{1413,1423} & & 1418 & $\delta_{\mathrm{s}} \mathrm{CH}_{3}+\delta \mathrm{COH}$ & Raman \\
\hline & 1460 & 1433 & $\mathrm{v}_{\mathrm{as}} \mathrm{CN}$ & FTIR \\
\hline 1451, 1458 & & 1448 & $\delta \mathrm{s} \mathrm{CH}_{3}++\delta \mathrm{CH}_{2}$ & Raman \\
\hline \multirow[t]{3}{*}{1487} & & 1478 & $\delta$ as $\mathrm{CH}_{3}+\delta \mathrm{CH}_{2}$ & Raman \\
\hline & 1676 & 1606 & $\underline{\mathbf{\delta} \mathbf{N H}_{2}}+v \mathrm{C}=\mathrm{O}$ & FTIR \\
\hline & 1591 & 1660 & $\underline{\mathbf{v C}=\mathbf{O}}+\delta \delta \mathrm{NH}_{2}$ & FTIR \\
\hline 2888 & & 2881 & $v_{\mathrm{s}} \mathrm{CH} 2$ & Raman \\
\hline 2924 & & 2929 & $v_{\text {as }} \mathrm{CH} 2+v_{s} \mathrm{CH} 3$ & Raman \\
\hline 2966 & & 2970 & $v_{\mathrm{as}} \mathrm{CH} 2+v_{\mathrm{s}} \mathrm{CH} 3$ & Raman \\
\hline 3025, 3013 & & 3024 & $v_{\text {as }} \mathrm{CH} 3$ & Raman \\
\hline \multirow[t]{5}{*}{3219} & & $?$ & $v \mathrm{OH}$ & FTIR \\
\hline & 3256 & & $\delta \mathrm{NH}_{2}+v \mathrm{CO}$ Fermi w/vNH & FTIR \\
\hline & & 3188 & ? (see discussion) & FTIR \\
\hline & 3333 & 3315 & $v_{\mathrm{s}} \mathrm{NH}_{2}$ & FTIR \\
\hline & 3427 & 3417 & $v_{\text {as }} \mathrm{NH}_{2}$ & FTIR \\
\hline
\end{tabular}

$\tau$-torsion; $v$-stretching; $\delta$ - deformation; $\rho$ - rocking; $\omega$-wagging; $\pi$ - out-of-plane deformation. 
Figure S2. INS spectra of Reline, urea and choline chloride (ChCl) collected using TOSCA

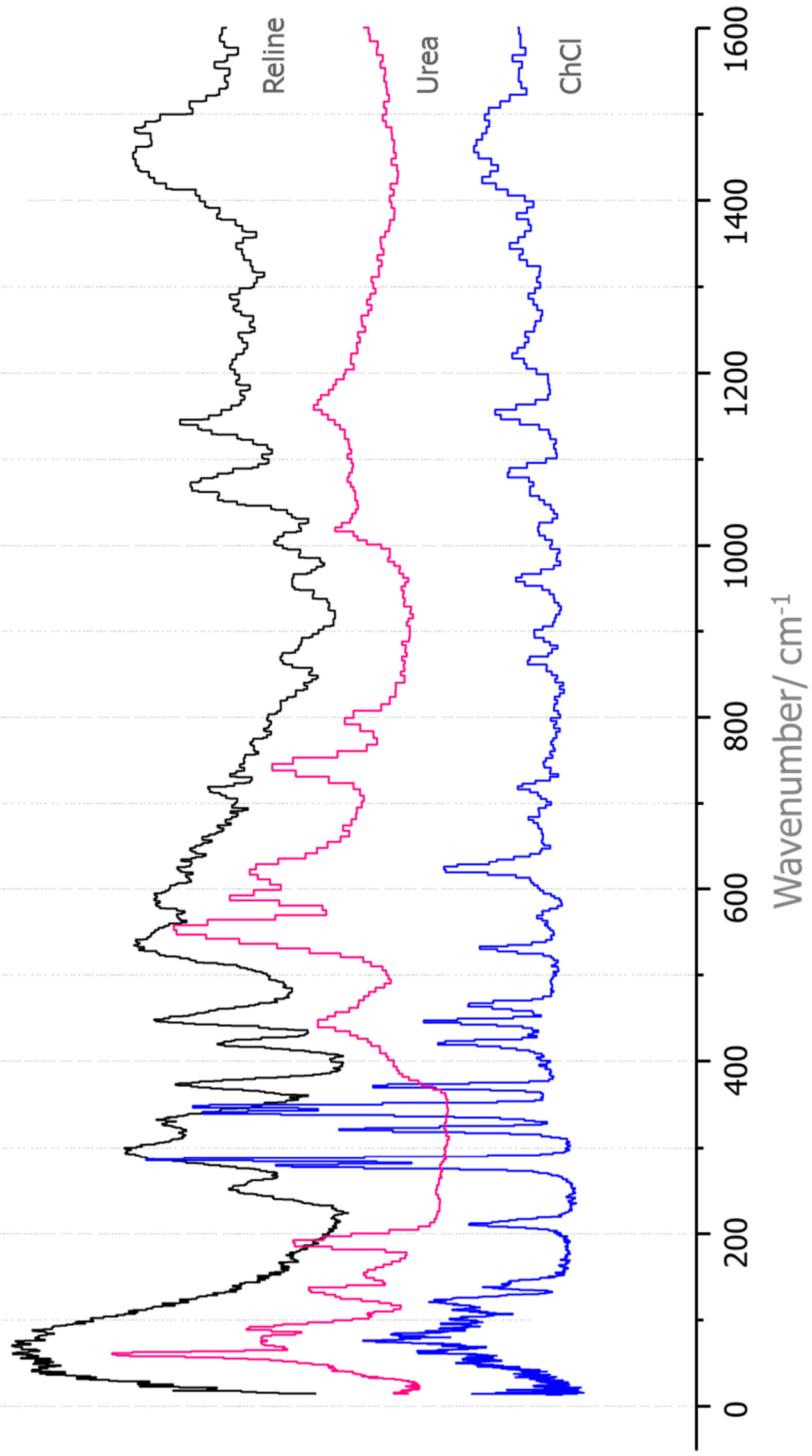


Figure S3. INS spectra of Reline, urea and choline chloride $(\mathrm{ChCl})$, collected using MAPS with incident energy (Ei) of a) $806 \mathrm{~cm}-1$, b) $2016 \mathrm{~cm}-1$ and c) $5243 \mathrm{~cm}-1$. Only small Q values in the range $0 \leq \mathrm{Q} \leq 9 \AA-1$ are represented.

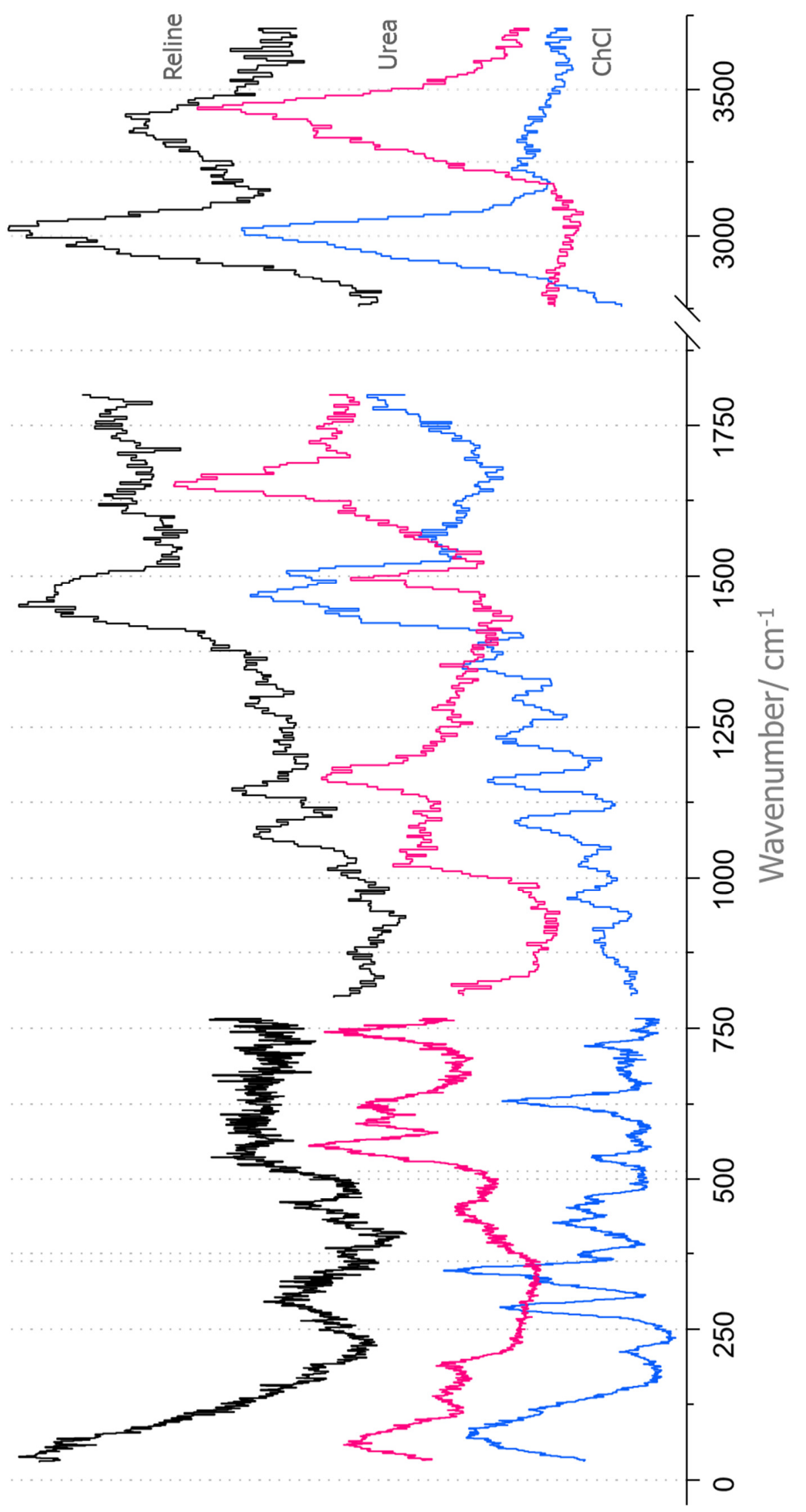


Figure S4. Dependence of energy resolution with energy transfer for the TOSCA instrument

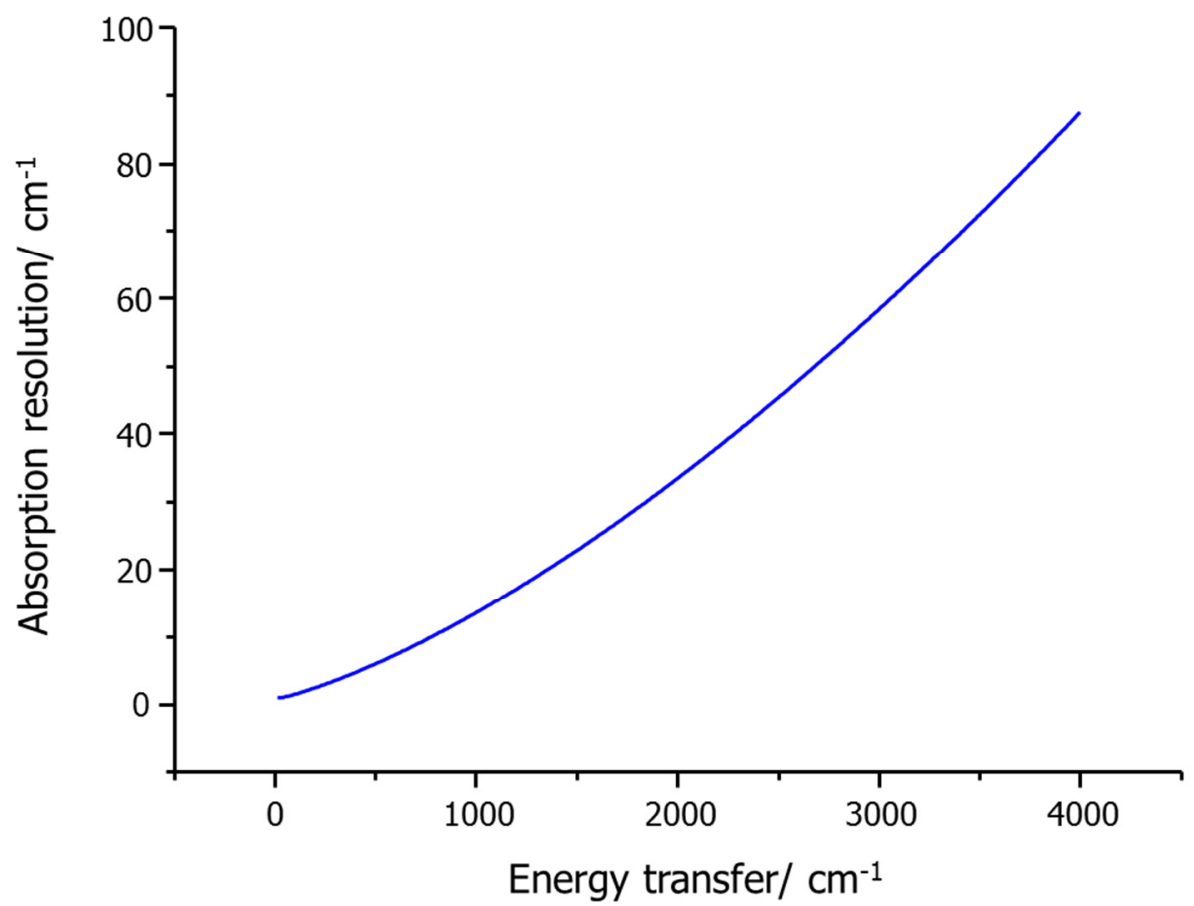

Figure S5. Raman spectra of urea (top), Reline (middle) and choline chloride (bottom)

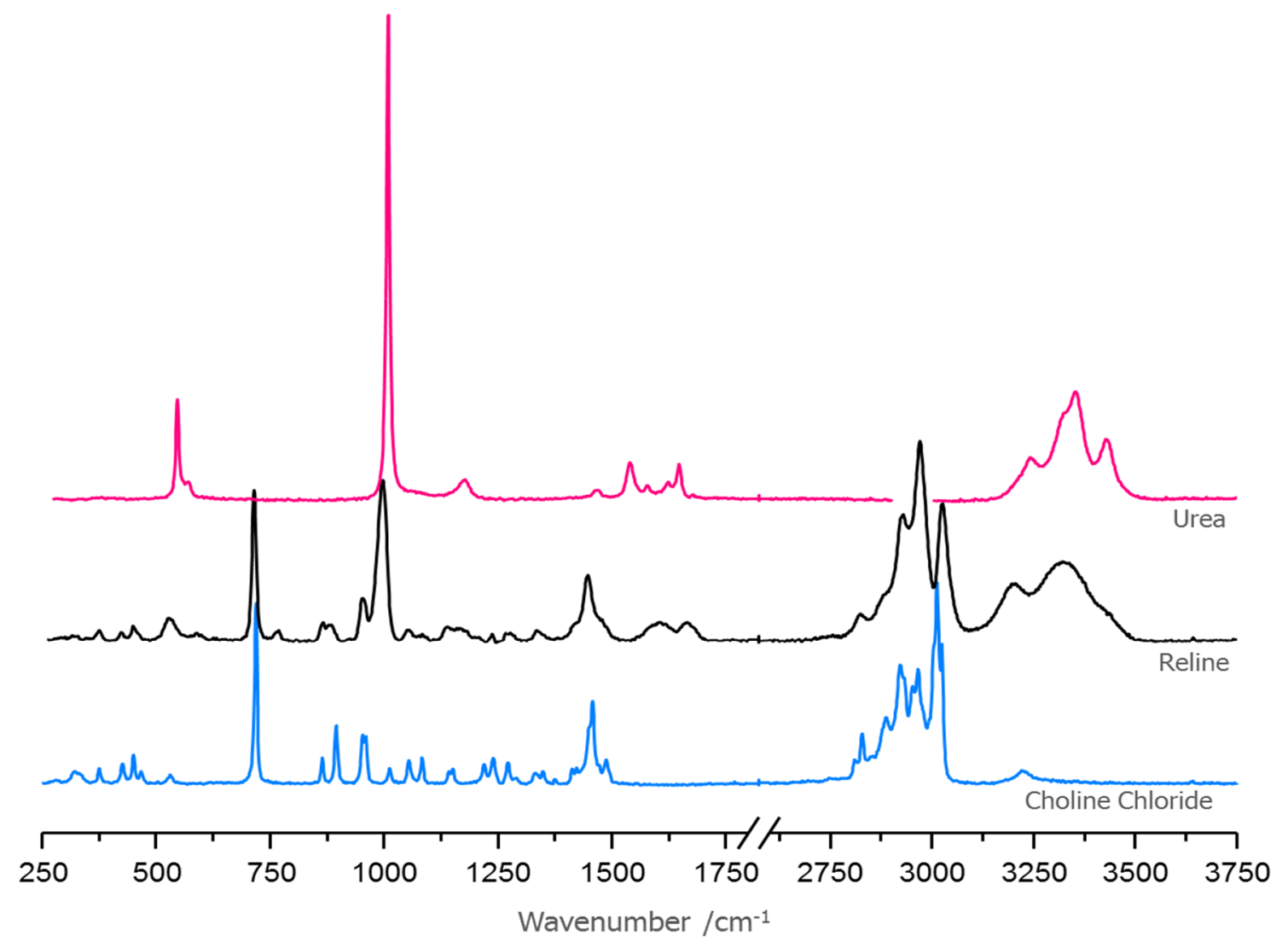


Figure S6. Comparison between Reline's experimental Raman spectrum and the one estimated by a discrete ab-initio calculation

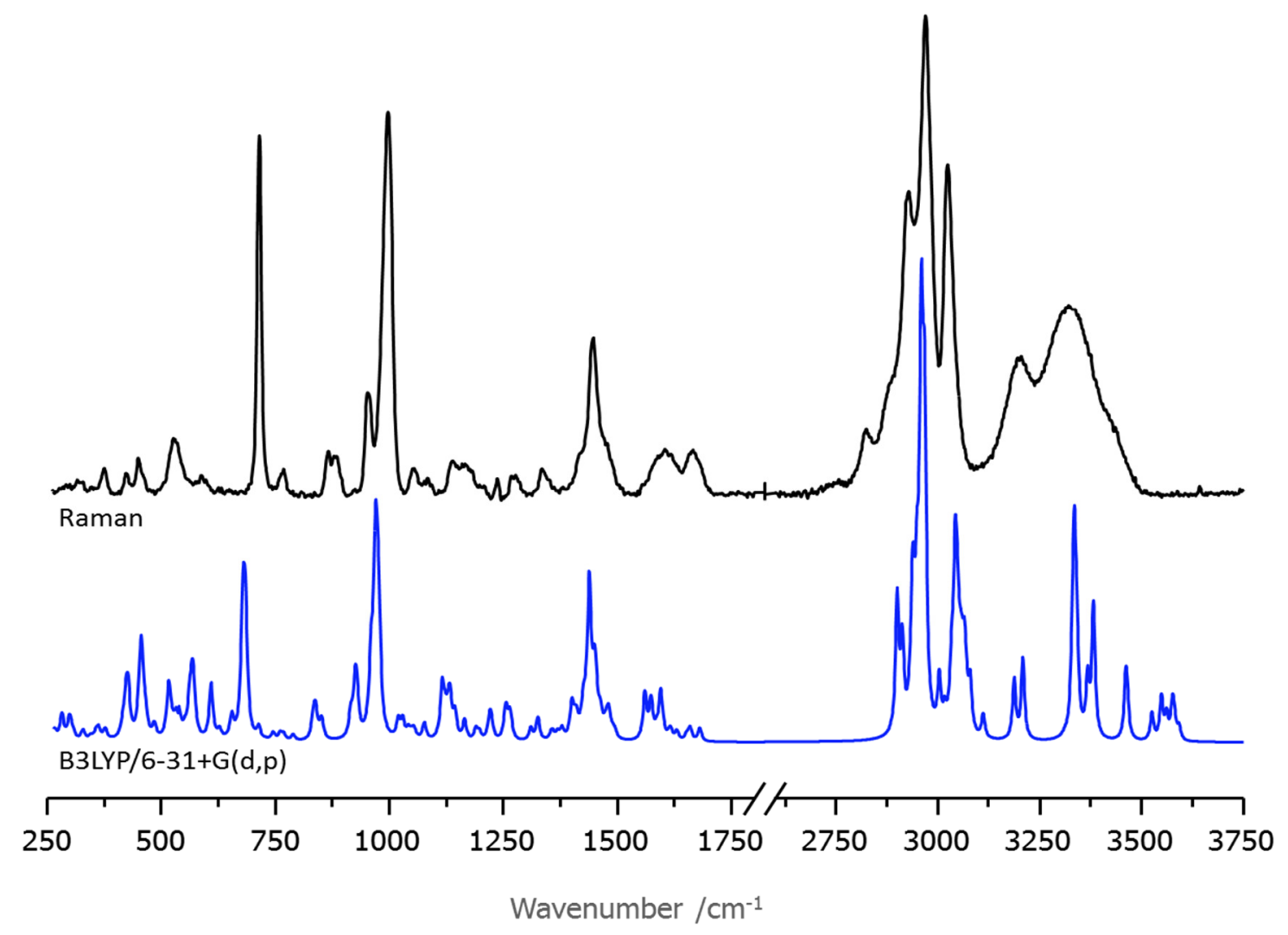

Figure S7. FTIR-ATR spectra of urea (top), Reline (middle) and choline chloride (bottom)

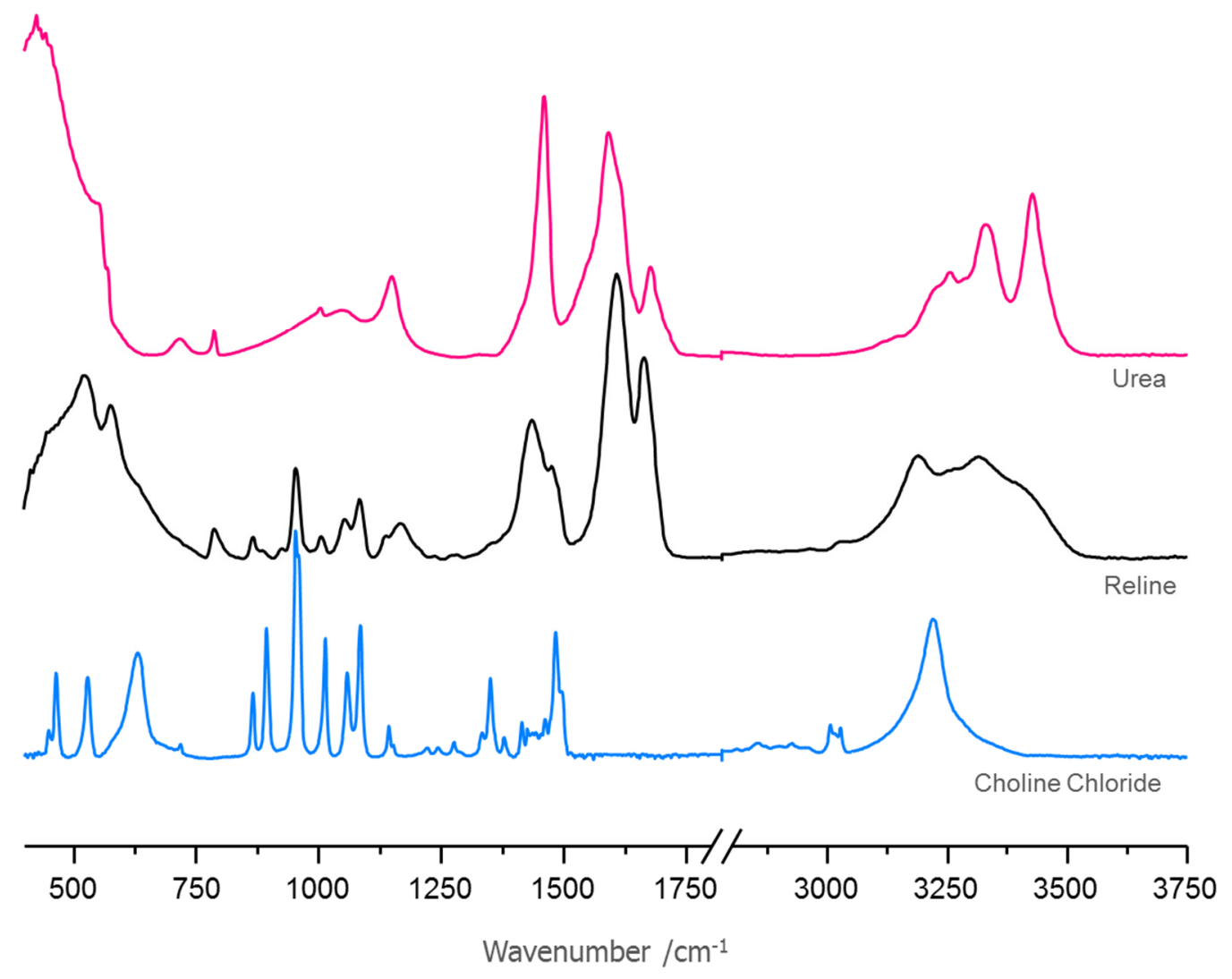


Figure S8. Comparison between Reline's experimental infrared spectrum and the one estimated by a discrete ab-initio calculation

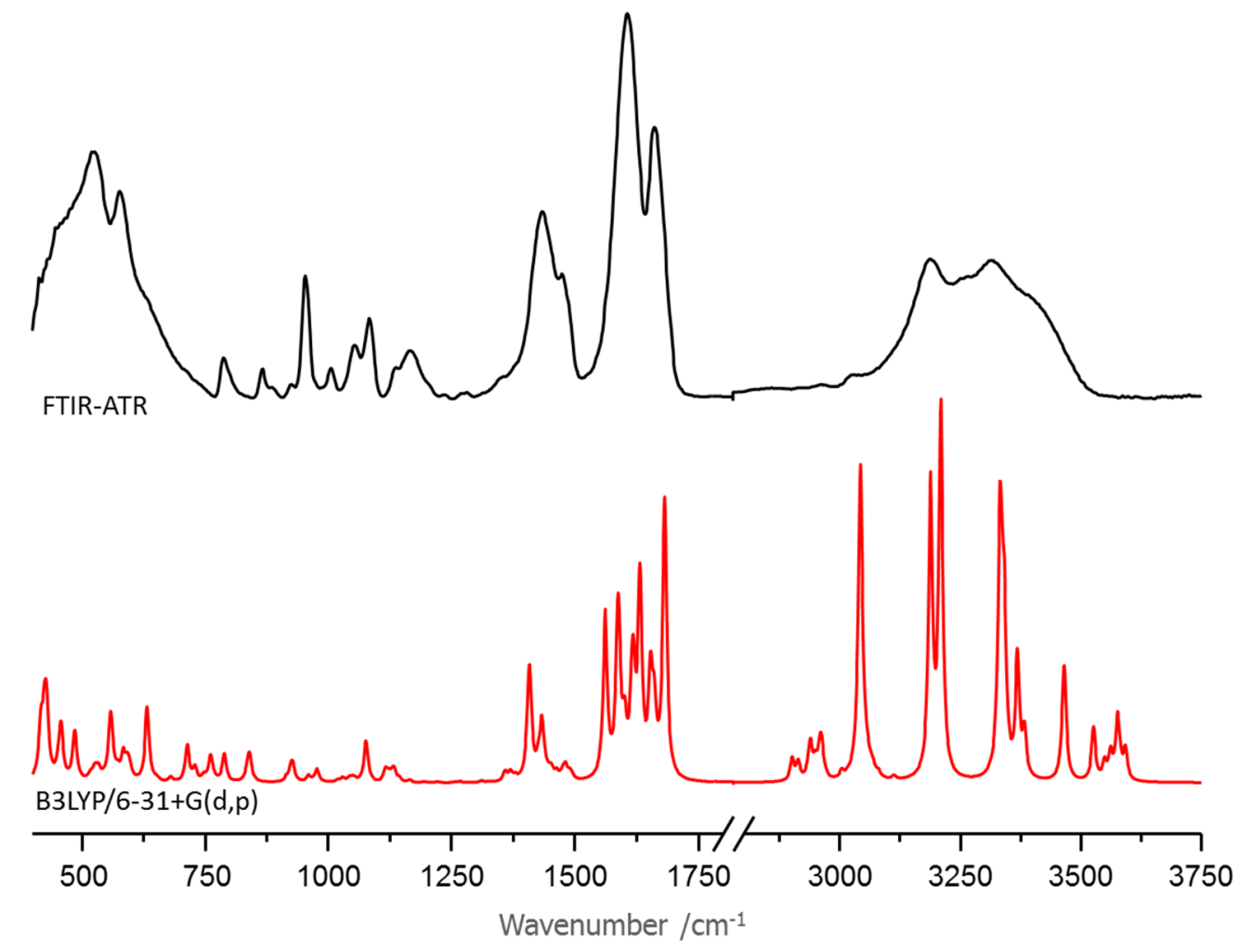

Figure S9. Raman spectra of Reline with increasing deuterium content

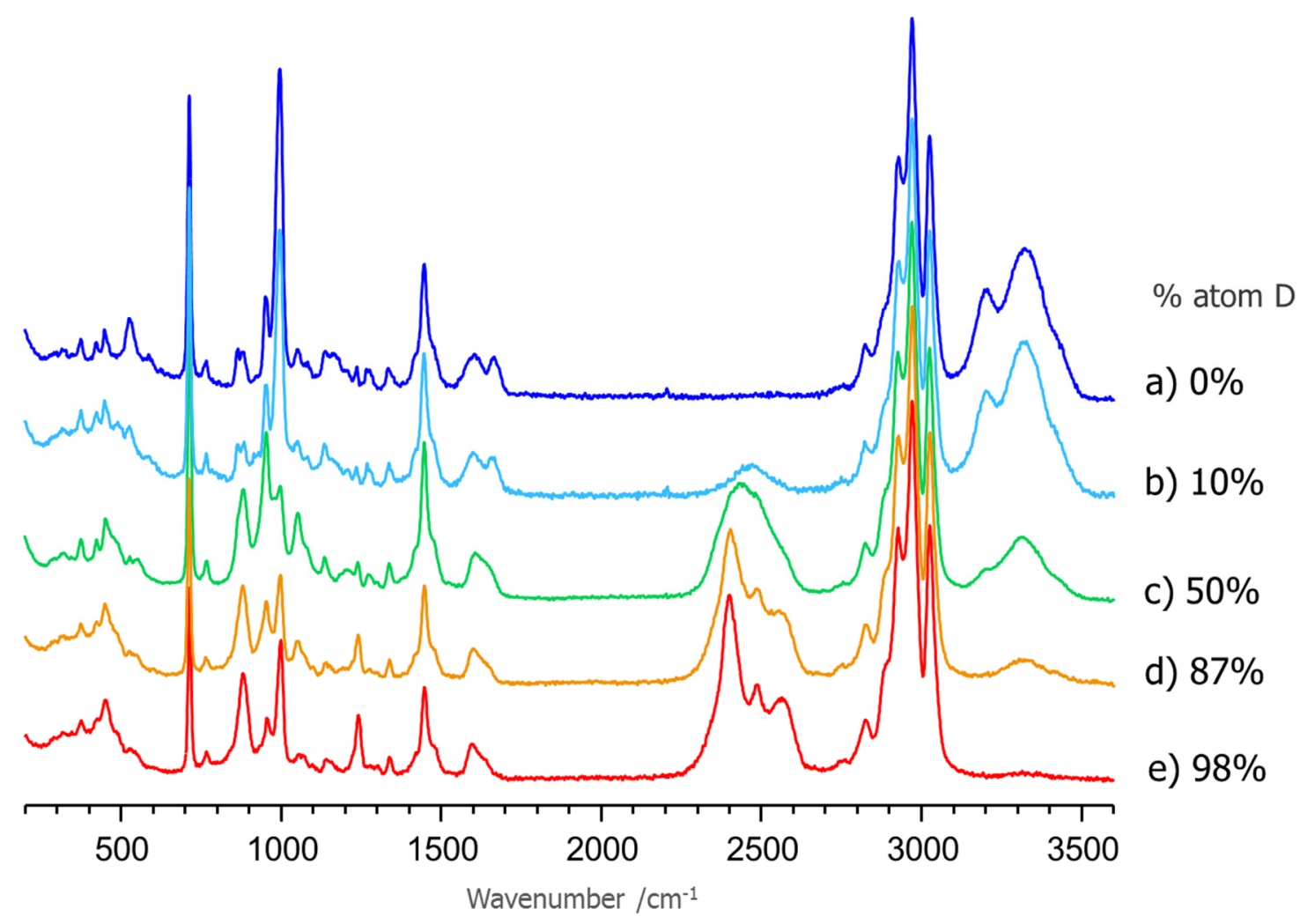


Figure S10. FTIR-ATR spectra of Reline with increasing deuterium content

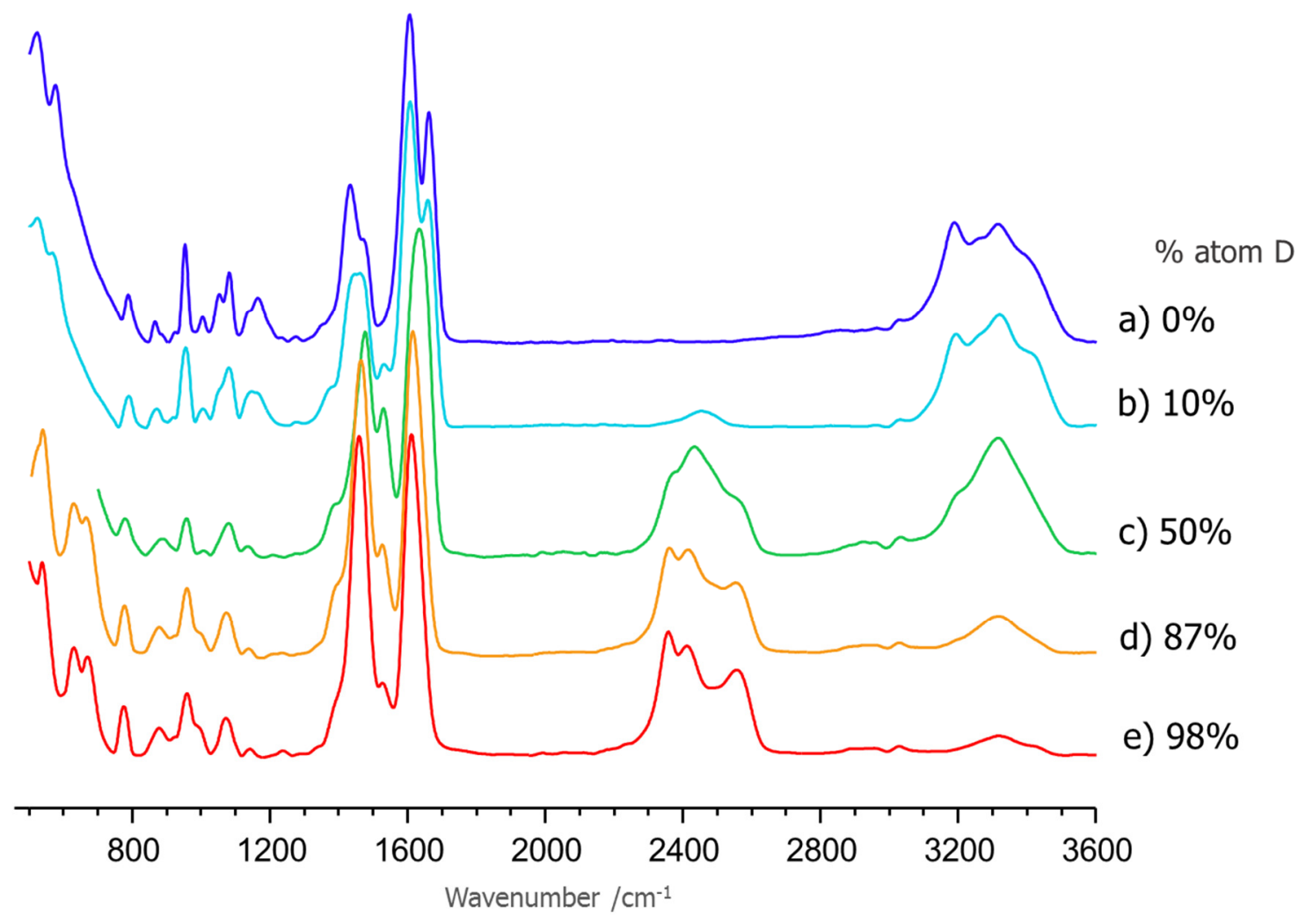

